Louisiana State University

LSU Digital Commons

1974

\title{
The Measurement of Sulfuric Acid Aerosol and the Total Sulfate Content of Ambient Air.
}

Ray Frank Maddalone

Louisiana State University and Agricultural \& Mechanical College

Follow this and additional works at: https://digitalcommons.Isu.edu/gradschool_disstheses

\section{Recommended Citation}

Maddalone, Ray Frank, "The Measurement of Sulfuric Acid Aerosol and the Total Sulfate Content of Ambient Air." (1974). LSU Historical Dissertations and Theses. 2744.

https://digitalcommons.Isu.edu/gradschool_disstheses/2744

This Dissertation is brought to you for free and open access by the Graduate School at LSU Digital Commons. It has been accepted for inclusion in LSU Historical Dissertations and Theses by an authorized administrator of LSU Digital Commons. For more information, please contact gradetd@lsu.edu. 


\section{INFORMATION TO USERS}

This material was produced from a microfilm copy of the original document. While the most advanced technological means to photograph and reproduce this document have been used, the quality is heavily dependent upon the quality of the original submitted.

The following explanation of techniques is provided to help you understand markings or patterns which may appear on this reproduction.

1. The sign or "target" for pages apparently lacking from the document photographed is "Missing Paga(s)". If it was possible to obtain the missing page(s) or section, they are spliced into the film along with adjacent pages. This may have necessitated cutting thru an image and duplicating adjacent pages to insure you complete continuity.

2. When an image on the film is obliterated with a large round black mark, it is an indication that the photographer suspected that the copy may have moved during exposure and thus cause a blurred image. You will find a good image of the page in the adjacent frame.

3. When a map, drawing or chart, etc., was part of the material being photographed the photographer followed a definite method in "sectioning" the material. It is customary to begin photoing at the upper left hand corner of a large sheet and to continue photoing from left to right in equal sections with a small overlap. If necessary, sectioning is continued again - beginning below the first row and continuing on until complete.

4. The majority of users indicate that the textual content is of greatest value, however, a somewhat higher quality reproduction could be made from "photographs" if essential to the understanding of the dissertation. Silver prints of "photographs" may be ordered at additional charge by writing the Order Department, giving the catalog number, title, author and specific pages you wish reprodursd.

5. PLEASE NOTE: Some pages may have indistinct print. Filmed as received. 
MADDALONE, Ray Frank, 1948-

THE MEASUREMENT OF SULFURIC ACID AEROSOL AND THE TOTAL SULFATE CONTENT OF AMBIENT AIR.

The Louisiana State University and Agricultural and Mechanical College, Ph.D., 1974 Chemistry, inorganic

Xerox University Microfilms, Ann Arbor, Michlgan 48106 
THE MEASUREAENT OF SULFURIC ACID AEROSOL

AND THE TOTAL SULFATE CONTENT OF AMBIENT AIR

\author{
A Dissertation \\ Submitted to the graduate Faculty of the \\ Louls lana State University and \\ Agricultural and Mechantcal College \\ in partial fulfillment of the \\ requirements for the degree of \\ Doctor of Philosophy \\ in \\ The Department of Chemistry
}

by

Ray F. Maddalone

B.S., Unfversity of Notre Dame, 1970

December, 1974 
The pursult of sclence has passed through the time of one-man research to the era of team research. It has been the author's great privilege to work with a collection of one of the most inventive and knowledgeable group of people in the LSU-BR Chemistry Department. To them go my best wishes in all their present and future endeavors. But most of all, my thanks and appreclation go to $\mathrm{Dr}$. PhIlip W. West, whose wisdom and guidance overcame the Impatience of youth.

The author would like to thank the Charles E. Coates Memorial Fund of the LSU Foundation, donated by George H. Coates, for expenses pertinent to the preparation of this Dissertation. The author would also like to acknowledge the support glven by RANN NSF Grant GI-35114X1, and NSF Grant GP-18081. 
ACKNOWLEDGEMENTS. . . . . . . . . . . . . . . . . . . . .

LIST OF TABLES............................ v

LIST OF FIGURES. ...........................

ABSTRACT................................. vil

PART I - INTRODUCTION......................... 2

CHAPTER I. Sulfurle Acld Aerosol as an Alr Pollutant.... 3

A. Background and Emisston Sources of Sulfuric Acid 3

B. Characterization and Health Effects of Sulfuric Acid Aerosol.........................

CHAPTER II. Previous Attempts at Measuring Sulfuric Acld

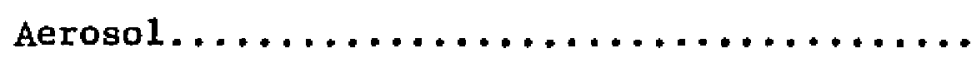

A. Measurement of Sulfuric Actd Aerosol as Protons. 9

B. Measurement of Sulfuric Acid Aerosol as Sulfate. 11

PART II - MEASUREMENT OF SULFURIC ACID AEROSOL...........

CHAPTER III. Separation of Sulfuric Aerosol from the

$$
\text { Gross Filter sample................ }
$$

A. Previous Attempts at the Separation of sulfuric Aerosol from the Gross Filter sample..........

B. Microdiffusion of Sulfuric Actd Aerosol from

Various Filter Media....................

1. Experimental. .....................

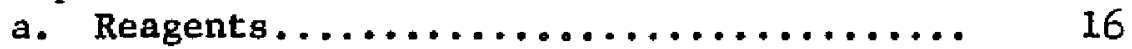

b. Apparatus...................... 17

c. Procedure....................... 18

2. Results and Dlscussion............... 21

a. Microdiffusion from Glass plates........ 21

b. Microdiffusion from Glass Fiber Filters. 28

c. Microdiffusion from Other Filter Media.. 32

3. Conclustons...................... 40 
CHAPTER IV. Reduction of Sulfate to Sulfur Dioxide via Thermal Degradation of Perimidylammonfum sulfate................... 41

A. Previous Attempts at Sulfate Reduction......... 41

1. Experimental...................... 42

a. Reagents...................... 42

b. Apparatus..................... 43

c. Procedure........................ 49

B. Results and Discussion................. 50

CHAPTER V. Measurement of Sulfuric Acid Aerosol and the Total Sulfate Content of the Ambient Alr. 65

A. Previous Attempts at Measuring Sulfurtc Acid

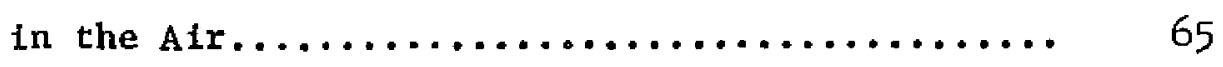

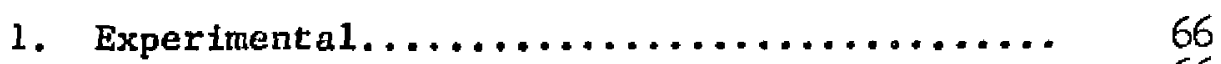

a. Reagents....................... 66

b. Apparatus...................... 66

c. Procedure....................... 67

1. Extraction Procedure (Total Sulfate Method)................. 68

1i. Diffusion-Pyrolysis Method (Sulfuric Acid Aerosol Method)....... 69

B. Results and Discussion................. 70

1. Total Sulfate Method.................. 70

2. Sulfuric Acid Aerosol Method............ 71

c. Summary.......................... 81

REFERENCES ................................ 82

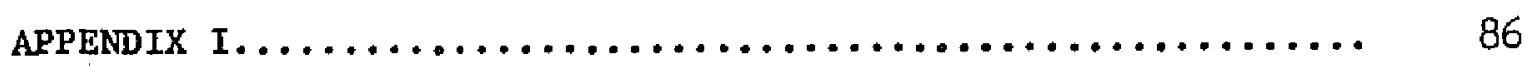

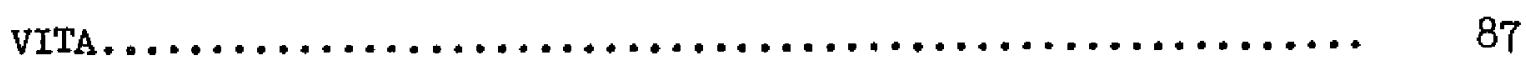


I. Diffuston at $195^{\circ}$ from Glass Plate Using Polished Petri Dishes - Effect of TIme............... 22

II. Results of Diffusion from a $16 \mathrm{~mm}$ Disc of Gilman A Glasg Fiber at $195^{\circ}$ After Vartous Washes.......... 29

III. Amount of Sulfurlc Acld Found on Glass Plate for Different Size Petrf Dishes and $8 \mathrm{~mm}$ Filter....... 34

IV. Prectsion of the Pyrolytic Sulfate Method......... 63

V. Coefficient of Vartance for the Extraction Procedure Analysis of Generated Aerosol Samples at Several Concentrations....................... 72

VI. Coefficient of Varlance for the Diffuston-Pyrolysis Analysis of Generated Aerosol Samples at Several Concentrations......................... 
1. Microdiffusion Apparatus................... 20

2. Microdiffusion of Sulfuric Acid from Glass Plates

vs. Temperature........................

3. Microdiffusion from Polished vs. Unpolished Petr1

Dishes.............................

4. Microdiffusion from Poco Graphite Filters for

3 Hours at $195^{\circ}$

5. Microdiffusion from Mitex Teflon Filters for

3 Hours at $195^{\circ}(\Delta)$ and for 6 Hours at $125^{\circ}$ (O).... 39

6. Combustion Tube and Injector................ 46

7. Combustion Train...................... 48

8. Differential Thermal Analysis and Differential Scanning Calortmeter of $(\mathrm{PDA})_{2} \mathrm{SO}_{4} \ldots \ldots \ldots \ldots \ldots \ldots$

9. Pyrolysis scheme........................ 56

10. Total Sulfur Analyzer Flow system Diagram.......... 59

11. Pyrolysis Calibration Curve.................. 62

12. Diffusion from Fluoropore Filters for 6 Hours at $125^{\circ}$ Using Sulfuric Acid Solutions............ 75

13. Diffusion from Fluoropore Filters for 6 Hours at $125^{\circ}$ Using Generated Sulfuric Acld Aerosols........ 
ABSTRACT

The advent of the energy crisis has placed a greater reliance on coal and other high sulfur fuels. When any sulfur-containing fuel is burned, sulfur dioxide is released as a by-product. By burning additional amounts of coal, we will be introducing greater amounts of sulfur dioxide into the air. Sulfur dioxide is a toxic pollutant in its own right, but by the action of alr, sunlight, and molsture, sulfur dioxide is converted to sulfuric acid aerosol. The main problem with an aerosol is its lack of mobllity as compared to a gas such as sulfur dioxide. The low mobllity of the acid aerosol raises the posstbility of high localized concentrations.

This Dissertation will discuss the measurement of sulfuric actd aerosol, including sampling, separation, and analytical fintsh. It was evident early in our work that most sulfate methods would not perform properly at the levels necessary ( 1 to $50 \mathrm{Hg}$ ). A new method for determining sulfate was developed where sulfate was preclpitated as the perlmidy lammonfum sulfate $\left[(\mathrm{PDA})_{2} \mathrm{SO}_{4}\right]$. When the (PDA) $\mathrm{SO}_{4}$ wag heated at $500^{\circ}$ in a nitrogen-purged oven, sulfur dioxide is quantitatively evolved. The West-Gaeke procedure was used to measure the evolved sulfur dioxide.

The sampling of the actd was accomplished by using a $0.5 \mu$ Fluoropore Teflon filter. Once a sample was collected, the sulfuric ac1d was separated from the gross afr sample by heating the f1lter to $125^{\circ}$ for 2 hours. A small petrl dish was placed over the afr sample and the acid was trapped on the instde of the dish by using a suitable 
absorbant. It was found that the amount recovered was dependent on the concentration of acid on the filter. There was, however, a plateau reached when 5 or more micrograms of actd were collected. By operating on this plateau, $86 \%$ of the sulfurlc acid was recovered from the filter. By coating the Inside of the petrl dishes with perimidylammonium bromide $(\mathrm{PDA}-\mathrm{Br}),(\mathrm{PDA})_{2} \mathrm{SO}_{4}$ was formed directly. Without any further treatment, the petrl dishes were heated in the pyrolysis oven and the sulfur dioxide evolved and measured.

The total sulfate content of a fliter was determined by extracting a filtered air sample with a 50\% methanol-water solution. The sulfate was precipitated by addition of $\mathrm{PDA}-\mathrm{Br}$, and the (PDA) $\mathrm{SO}_{4}$ formed was pyrolyzed. By knowing the sampling flowrate and time of sampling, the amblent concentration of sulfuric acid or total sulfate could be calculated from the amount of sulfur dioxide evolved. 
PART I

INTRODUCTION 
Modern man prides himself on his accomplishments in taming the world and molding it after his fashion. Some feel this progress has been but a shallow victory in light of the price the environment has paid. The problem of pollution, however, is an old one, as early man can vertfy. He, too, probably turned from those first cooking fires with tears in his eyes and a gag in his throat and asked, "Is this progress?" 


\section{CHAPTER I. SULFURIC ACID AEROSOL AS AN AIR POLLUTANT}

A. Background and Emission Sources of Sulfuric Actd

In 1273, the English thought London's alr was so bad that they banned the burning of sea coal. In 1661 , John Evelyn submitted to Charles II a pamphlét entitled, "Fumifuglum, or the Smoake (sic) of London Dissipated", In which he predicted many of the problems we have today. ${ }^{2}$ The Londoner's distress was due to burning coal in poorly designed furnaces. The resulting smoke contalned near-toxic, toxic, and odoriferous components of which sulfur dloxide was one of the more toxic products. Since the energy crisis is upon us, the shortage of domestic gas and ofl supplies will force us to use greater amounts of coal. Even Low sulfur coal contains more sulfur than a clean fuel like natural gas, and the most plentiful sources of coal in the United states are not of the low sulfur varlety. Thus, the United States Congress is debating an upward revision of the maximum allowable sulfur dioxide emisston concentrations in order to take advantage of the large coal reserves in the United States. Any retreat from present standards will allow widespread use of coal which prevfously wasn't possible due to its sulfur content. The revision of the Alr Quality Act will also benefit industrial procedures like coke production and ferrous and non-ferrous metallurgical processes whtch entt sulfur dioxide as a by-product. 2 All Industries will be able to use cheaper, higher sulfur fuels with less pollution control of sulfur dloxide. The net result will be an Increase of the sulfur dioxide introduced into the environment. Sulfur dioxide by itself is harmful, but it has been well documented that in the presence of oxygen, molsture, and sunlight, 
sulfur dioxide is converted to sulfuric acid. 9 The toxicity of sulfuric acid is much greater than that of sulfur dioxide, and at the same time the sulfurtc actd is in the form of a mist. While the sulfur dioxide emitted from any given source will be dissipated in a large volume of alr because of its wobility as a gas, the sulfurlc acid mist will be much less mobfle, and Its effect will be localized at the point of its formation. The low mobllity and the localized effect of sulfuric acid mist is especially significant when one realizes that some sulfuric acid 1s produced directly by most sulfux dioxide sources, the amount produced varying according to operational conditions.

Looming on the horizon is a new source of sulfuric acid aerosol, the catalytic converter. Though designed to convert carbon monoxide to carbon dioxide, the catalytic converter has recently ${ }^{4}$ been shown capable of oxidizing sulfur dioxide to sulfur trioxide. The sulfur trioxide in the humid atmosphere of a car's exhaust system would be emitted as sulfurtc actd. The danger here $1 \mathrm{~s}$ one of localized increases of sulfurtc actd causing harm to pedestrians near heavily traveled roads. As of this writing, plans are still set to equip cars with catalytic converters in the 1975 model year.

B. Characterization and Health Effects of Sulfuric Acid Aerosol

Since afr pollution studies were initlated, sulfuric acid has been identified in the atmosphere. The toxictty of sulfuric acid in gross quantities is well known, but until recently the effect of sulfurtc actd aerosol has not been investigated. Amdur ${ }^{5, \theta}$ exposed laboratory animals to various amounts of sulfuric acid aerosol. She found 
that exposure to sulfurtc actd resulted in narrowed alr passages caused by bronchostenosts, mucosal swelling or tncreased secretion. As a result of these effects, people who already have trouble breathing (the old, asthmatic, or heart patients) can be killed not by the direct corrosive qualities of sulfuric acid, but by the resplratory strain that sulfurlc actd aerosol places on an already stressed person.

The correlation between high concentrations of sulfuric acid aerosol and deaths resulting from respiratory distress was not immediately apparent. In most afr pollution episodes many other pollutants were present at high levels. For example, during the Meuse Valley fog ${ }^{7}$ of 1930 , sulfur dloxide levels as high as 8 ppr were found. That level was high, but not fatally toxlc, yet 63 people were killed in a 5 -day period. Fricket ${ }^{7}$ was the flrst to note that only those areas that were subjected to emissions 1 rm heavy industry and fog exhibited excess mortality rates. Fricket also found that in previous fogs, excess mortalities (deaths above statistical average for a given perlod of time) occurred during times of industrial activity. Fricket warned that if the same event happened in London, death rates as high as 3,200 could be expected. The disaster that Frfcket predicted took place in London in 1952. For the period of December 5 through 9 a total of 3,500 to 4,000 excess mortalities was recorded. The sulfur dioxide levels only reached $1.34 \mathrm{ppm}$, but the suspended particulate matter ${ }^{8}$ was found to be 4,500 $\mu \mathrm{g} / \mathrm{m}^{3}$. This extremely high concentration of suspended material, and the fact that all deaths were characterfzed by respiratory tract Irritation, implicated some agent other than sulfur dioxide. The prime candidate was sulfurlc acld whlch as we have already stated can be formed in the atmosphere by photo-oxidation of sulfur dioxide. The end 
result is the formation of a highly toxic atmospheric aerosol which contains sulfuric actd by itself or attached to suspended particulate matter.

Another facet of the sulfuric acid toxtelty problem is the result of the relationship between particle size and depth of penetration Into the lungs. Particles above $2 \mu$ in d dameter are normally trapped in the upper respiratory tract and expelled, while particles In the $0.1 \mu$ to $2 \mu$ range will penetrate deep into the lung, where the most damage can occur. Several researchers ${ }^{9-12}$ have studied the particle slze distribution for sulfate aerosols. Their results are in good agreement as a range of 0.35 to $0.45 \mu$ for the mass median diameter was found. One study ${ }^{11}$ commented that 80 to $90 \%$ of the sulfate measured was in the respirable range. Andur 5 confirmed that the effect of the aerosol depended on particle size. She found as the particle size was decreased, an increase was noted in the flow resistance to respiration in animals. Other sulfates produced similar results. A comparison of zinc ammonium sulfate, zinc sulfate and ammonium sulfate showed zinc ammonium sulfate to be the worst irritant. When zinc ammonium sulfate and sulfurtc actd aerosol of equal particle size were compared, sulfuric acid was the greater irritant.*

This dependence on particle slze was aptly illustrated by the Donora, Penngylvanta fog (1948) whtch kflled 17, and left $43 \%$ of the 14,000 people affected. ${ }^{13}$ Though other air pollution eptsodes have occurred in the U.S. (Detroit 14 and New York ${ }^{15}$ ), the Donora eplsode

\footnotetext{
*This comparison has not been explored completely. For some of the added problems involved in the comparison, see Amdur ref. 5.
} 
was unique since the calls for assistance ceased on the fifth day even though the fog remained quite dense. It is quite posstble that the fog droplets containing sulfuric actd underwent a physical change. A simple maturation of the fog droplets due to a change in meteorological conditions could easily have converted the small toxic droplets to large non-toxic droplets. Thus the fog remained, but its toxicity decreased. The lack of any suitable method to measure sulfuric actd as such precludes any direct statement on the actual agent responsible for the deaths in the above air pollution episodes. The weight of evidence strongly suggests that sulfuric actd aerosol was the killer. 
GHAPTER II. PREVIOUS ATTEMPTS AT MEASURING SULFURIC ACID AEROSOL

Once sulfurtc actd and sulfates were Implicated as severe respiratory irritants, Investigators began to look for sulfuric acid In the alr samples with a varlety of methods. The accuracy of their results not only depended on the skill of the investigator, but more often on his or her Iuck in making the proper assumption. Most investigators assumed that either the total acidity or the total sulfate found was due to the sulfuric actd. In some samples this assumption would be valid, but in most it would not. Thus, the literature is littered with terms like "acid sulfate", "particulate acid" or "fixed soluble sulfate", depending upon whether the method employed measured protons or the sulfate anion. Such terms only hide the fact that there is no method avallable today for the measurement of sulfurlc actd as an identiflable specles. The numbers that have been obtained are the result of falrly complicated or tedious procedures. In order to appreclate the problem better, one must realize that in a city like Pittsburgh a typical sumer air sample would contain approximately $12-16 \mu \mathrm{g} / \mathrm{m}^{3}$ of sulfuric acld aerosol. 10 Sulfurlc acid aerosol was measured by the same method in London, and concentrations of $7 \mu \mathrm{g} / \mathrm{m}^{3}$ and $18 \mu \mathrm{g} / \mathrm{m}^{3}$ were found in summer and winter, respectively. ${ }^{18}$ Thus, any method used must be quite sensitive unless extremely large air samples are to be collected.

The above values can only be uged to Indicate the concentration of sulfuric actd found in the atmosphere. Because of the sampling procedure used (collection on Whatman No. 1 filter paper), alkaline materials present in the air sample would react with the sulfurtc actd collected on the filter's surface, and reduce the amount of acid measured. 
One must undexstand that an air sample is mostly particulate matter of which sulfuric acid comprises less than $1 \%$. The posalbility of topochemical reactions occurring between carbonates, metal oxides or fly ash, and sulfuric acid increases as the unused surface of the filter is decreased during prolonged sampling. Thus, if large samples are taken, the posstbility of interference is increased and the results of the method is suspect. A short review of sulfuric acid aerosol methods based on proton or sulfate measurements follows.

A. Measurement of Sulfuric Acid Aerosol as Protons

Early investigators using the measurement of acidity as a measure of sulfuric ac1d concentration assumed that the actdity found was directly related to sulfuric actd aerosol. As information on the make-up of air samples grew, Investigators realized that other actdic compounds existed in the atmosphere. Later methods employed corrections for this possibility. Coste and Courtier ${ }^{17}$ removed the sulfur dioxide from an air sample and then saturated the resultant air stream with water vapor. The sulfuric acid aerosol particles would act as nuclet, so that sulfurtc actd could be condensed in a flask immersed in ice. The acidity was measured by direct titration. One of the drawbacks of this approach was the small sample $\left(1 \mathrm{~m}^{3}\right)$ collected over a long perfod of time (24 hours). Goodeve ${ }^{18}$ recommended filtering a1r samples with asbestos-packed Gooch crucibles, but that method was too slow and the filtratton efficiency varied. Mader, et al. ${ }^{19}$ used Whatman No. 4 filters, that had been washed in coplous amounts of distilled water and then dried, to sample the Los Angeles atmosphere. After a sample wes collected, the filters were place in a 
flask and macerated, the pH was measured. Mader found sulfurlc actd aerosol concentrations to be $0.036 \mathrm{ppm}$ or $36 \mu \mathrm{g} / \mathrm{m}^{3}$. Th1s number is high, and probably is the regult of sulfur dioxide adsorbing on the filter surface and then oxidizing to sulfuric acid. Mader mentioned this as a drawback, especially in humid air samples.

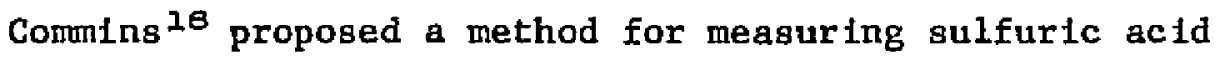
aerosol by titration to $\mathrm{pH} 7$ with acid after a known excess of sodium tetraborate was added. Commins' method took into account interferences such as sulfur dioxide and basic gases, but it could not differentiate between sulfuric actd and other actd components.

Acid Indicators have been used in a variety of ways for qual1tative measurements of actdity in air samples. Waller ${ }^{20}$ collected London air by impaction on glass slides coated with gelatin containing thymol blue. When viewed under a microscope, strongly acldic droplets were seen as pink spots. Derre and Pfeifer ${ }^{21}$ used a simflar approach except the plates were coated with nitrocelluloge and $5,5^{\prime}$-methylenedisalicylic acid. After exposure to the atmosphere, the plates were heated producing red spots where the acid droplets landed. Horstman and Wagman ${ }^{22}$ collected sulfuric acid aerosol on a slide coated with Iron deposited by vacuum distillation. The particle size was estimated by viewing the size of the reaction site on the iron $f 11 \mathrm{~m}$. Honma and Sakito ${ }^{29}$ used a photo-electric colorimeter to quantitatively measure the sulfuric acid aerosol collected on the metal film.

In sumnary, most of these methods make the assumption that all acldity is due to sulfuric actd in the atmosphere. Those methods that attempt to measure sulfurtc actd specifically, require complicated or tedious procedures. 
B. Measurement of Sulfuric Acid Aerosol as Sulfate

In this section a review of sulfate methods will be presented. Some researchers who applied these methods to an air sample made the assumption that all sulfate present was due to sulfuric acid. Andronov, et a1. ${ }^{24}$ simply washed a fllter with aqueous-acetone or ethanol mixtures and measured the "sulfurlc acld" as sulfate with barlum rhodizonate. Obviously the sulfate measured did not correspond to sulfuric acid, but was a measure of the total sulfate content of the air sample. Capkeviclene ${ }^{25}$ collected an air sample in distilled water. The sulfate was precipitated by addition of benzidine. The benzidine sulfate was isolated and coupled with thymol to produce a red product. The Intensity of the coloration was proportional to the amount of benzidine sulfate 1solated. Bavika, et al ${ }^{28}$ measured sulfurid actd by impingement in distilled water followed by the addition of ammonfum vanadate, which produced a yellow solution.

E111s 27 passed an air sample through a bubbler containing hydrogen peroxide. Any sulfur dloxide present in the afr sample would

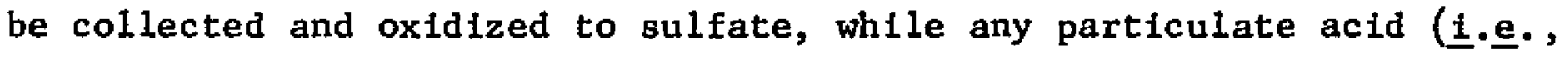
sulfurlc acid) would be scrubbed from the air flow. The same air was analyzed for its sulfur dioxide content by a redox reaction with lodine. The sulfate content of the hydrogen peroxide trap was determined, and the amount of sulfate due to the oxidation of sulfur dioxide was subtracted. The value left was considered by Ellis to be the sulfuric acid content of the alr sampled. Ellis overiooked (or did not know in 1931) that soluble sulfates were present in an alr sample. Even sulfates like calctum sulfate are soluble at the microgram level. Thus, 
without a prior separation step to remove the sulfurlc acld from the gross afr sample, the measurement of the sulfate content will only provide data on the total sulfate content of the sample.*

*For a further summary of sulfate methods see references 28 through 32 . 
PART II

MEASUREMENT OF SULFURIC ACID AEROSOL 


\title{
CHAPTER III. SEPARATION OF SULFURIC ACID AEROSOL
}

FROM THE GROSS FILTER SAMPLE

\begin{abstract}
A. Previous Attempts at the Separation of Sulfuric Acid Aerosol From The Gross Filter Sample
\end{abstract}

As was shown In the previous Chapter, values found for the acidity or sulfate content of an air sample are not a true measure of the concentration of sulfuric acid. Simply measuring the actdity or sulfate content of a collected air sample will only give values for the net acidity (since other acidic or alkaline materials are present) or total sulfate (since other sulfate species are present). The preferred mode of analysis would be to analyze for sulfate, since the sulfate will always be there, while protons tend to find a base and react before they have been determined. But before one could analyze for sulfuric acid as sulfate, a separation step must be applied to remove the sulfuric acld from the gross alr sample. The lack of an adequate pre-analysis separation step has prevented the measurement of sulfuric acid aerosol as sulfate.

Several Investigators have attempted to separate sulfuric acid aerosol from the gross air sample either by extraction or by selective distillation. Barton and McAdie 33,34 have published papers dealing with glass fiber filter pretreatment, as well as on the selective extraction of sulfuric acid from Nucleopore polycarbonate membrane filters. Their method, using 1-propanol, looked extremely promising, but recently ${ }^{35}$-propanol has been shown to extract ammontum sulfate and possibly other sulfates. Experiments described in this Dissertation have confirmed that 1-propanol will not selectively extract sulfuric 
acid. Also, Barton and McAdie's method of pretreating glass fiber filters was found to be inadequate. The evidence for this will be discussed in the following section.

Recently Leahy, et $\underline{\text { al }},{ }^{36}$ have proposed benzaldehyde as a selective solvent for sulfuric acid. Separations based on the use of this solvent appear to be free of interferences, and open the door to the use of any common sulfate method, once the sulfuric acid is removed from the gross sample. The separation procedure, however, was tested using samples well above normal environmental levels.

Since sulfuric actd is volatile compared to most compounds present in a filtered air sample, Dubols, et al., 37 sought to isothermally distill or micro-diffuse the sulfurlc acid from the surface of the filter. Their method consisted of taking a $47 \mathrm{~mm}$ diameter disc from an $8 \times 10$-inch glass fiber filter. This filter disc was covered by a petri dish whose inslde top had been coated with sodfum hydroxide. The whole apparatus was placed in a nitrogen-purged oven and heated overnight at $195^{\circ}$. The sulfuric actd diffused from the glass fiber to the sodium hydroxide, and was trapped. The following morning the tops were washed with a small amount of water, and the sulfuric acld was determined as sulfate by any one of a number of methods. Since this approach showed promlse, we Initiated a tracer study to investigate whether some sulfuric acid could have been lost in the sampling procedure, and whether or not an absolute amount of sulfuric actd was separated from the filter. 
B. Microduffusion of Sulfuric Acid Aerosol from Various Filter Media

\section{Experimental}

\section{a. Reagents}

Absorbing Solution - Two grams of reagent grade sodium hydroxide were dissolved $1 \mathrm{n} 5 \mathrm{ml}$ of water and made up to $100 \mathrm{ml}$ with absolute ethano1. This solution was made fresi datly. Sodium Hydroxide - Reagent grade, low in carbonate from Fisher Scientific Company.

Ammontum Sulfate - Reagent grade from Fisher Scientific Company .

Ethanol - Absolute ethanol from U. S. Industrial Chemicals Company.

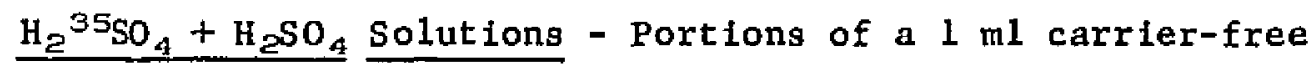
$\mathrm{H}_{\varepsilon}{ }^{35} \mathrm{SO}_{4}$ solution containing $5 \mathrm{mc} / \mathrm{ml}$ from New England Nuclear were added to $0.01 \mu \mathrm{g} / \mu \mathrm{l}, 0.1 \mu \mathrm{g} / \mu 1$ and $1.0 \mu \mathrm{g} / \mu 1$ sulfuric actd solutions to give an approprlate activity $(\sim 40,000$ to $70,000 \mathrm{cpm})$. The sulfuric acid was reagent grade from Mallenkrodt Chemical Works. p--Dioxane - Reagent grade from Matheson, Coleman and Bell. Naphthalene - Recrystallized from ethanol, reagent grade naphthalene was obtained from Matheson, Coleman and Bell. 2,2'-p-Phenylenebls-(5-phenyloxazole) - the POPOP was scintillation grade from Matheson, Coleman and Bell. 2,5-D1phenyloxazole - the PPO was scintillation grade from Matheson, Coleman and Bell:

Scintillation Cockta1l - $300 \mathrm{~g}$ of naphthalene, $15 \mathrm{~g}$ of PPO and $0.15 \mathrm{~g}$ POPOP were placed in 3 liters of p-dioxane. To $17 \mathrm{ml}$ of 
this solution, 3 ml of water rinses were added, bringing the total volume in the scintillation vial to $20 \mathrm{~m} 1$.

b. Apparatus

Oven - Sargent Analytical Oven (low gradient) equipped with a nitrogen purge.

Pyrex Petrl Dishes - Petr1 dish bottoms (Corning No. 3160) approximately $49 \mathrm{~mm} \mathrm{~m} \times 14 \mathrm{~mm}$ were used. The bottoms were used as purchased but with the edges ground to give a smooth seal with the glass plates.

Glass Vials - Vials of $15 \mathrm{~mm}, 19 \mathrm{~mm}$, and $25 \mathrm{~mm}$ OD were cut $\sim 5 \min$ from the bottom to provide dishes of vartous it's. Also, several more dishes were made from Pyrex tublng of 8 and 11 man diameter.

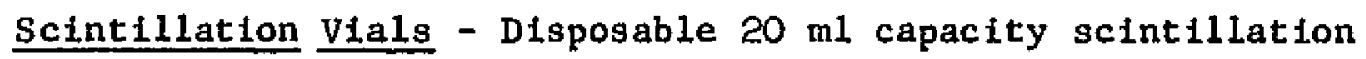
vials of Kimble No. 74500 or equivalent were used.

Plate Glass - Single strength window pane glass was cut into 63 mom squares.

Plpets - Radioactive solutions were plpetted with an Eppendorf 10 or $50 \mu 1$ capacity pipet.

Ltquid Scintillation Counters - All counting was done on either a Beckman Liquid Scintillation System II or Beckman LS-250 Liquid Scintillator.

Thermogravimetric Analyzer - Dupont $950 \mathrm{TGA}$.

Filters - The following filters were tested fox their microdiffusion qualities:

Mitex (Teflon) from the Milipore Corporation (5.0 $\mu$ ) Solvinert from the Millipore Corporation $(0.5 \mu)$ Nucleopore from General Electric $(1.0 \mu)$ 
Graphtte fliter from Spectrogram Corporation; North Haven, Connecticut

Whatman 41

Gelman A glass fiber filter from Gelman Instrument Company.

\section{c. Procedure}

In order to approximate a sulfuric acid aerosol, 10 to $50 \mu 1$ of the appropriate $\mathrm{H}_{2} \mathrm{~S}^{35} \mathrm{O}_{4}$ solution were placed on the glass plate or the fllter media and dried for $15 \mathrm{~min}$. at $80^{\circ}$. No $\mathrm{H}_{2} \mathrm{~S}^{35_{0}} \mathrm{O}_{4}$ was $10 \mathrm{st}$, although the water was removed.

The apparatus used (Figure 1) differed slightly from that of Dubois. 37 Instead of using both a top and bottom petri dish, only one dish was used (as the top) and a treated glass plate served as a bottom. This configuration approximated that of Dubols while allowIng the entire Inside of the petri dish to be coated.

The preheated $\left(60^{\circ}\right)$ petrl dish was coated with $0.15 \mathrm{ml}$ of the sodium hydroxide solution just before it was used. This minimized absorption of carbon dioxide from the air. After the tops were placed over the glass plates or filter media, the entire apparatus was placed In an oven at an appropriate temperature and time. The oven was constantly purged with nitrogen and a vent line was run into a bottle of $1 \mathrm{M}$ sodium hydroxide to prevent any contamination of the laboratory from volatilized $\mathrm{H}_{2} \mathrm{~S}^{35_{0}} \mathrm{O}_{4}$.

Labeled standards were placed on the glass plates or on the filter media and treated the same as the samples except they were not microdiffused. All data on the percentage recovery on sodium hydroxide as wel1 as mass balance data were based on a comparfson to these nonmicrodiffused standards. 
FIGURE 1

MICRODIFFUSION APPARATUS 


\section{DIFFUSION APPARATUS}

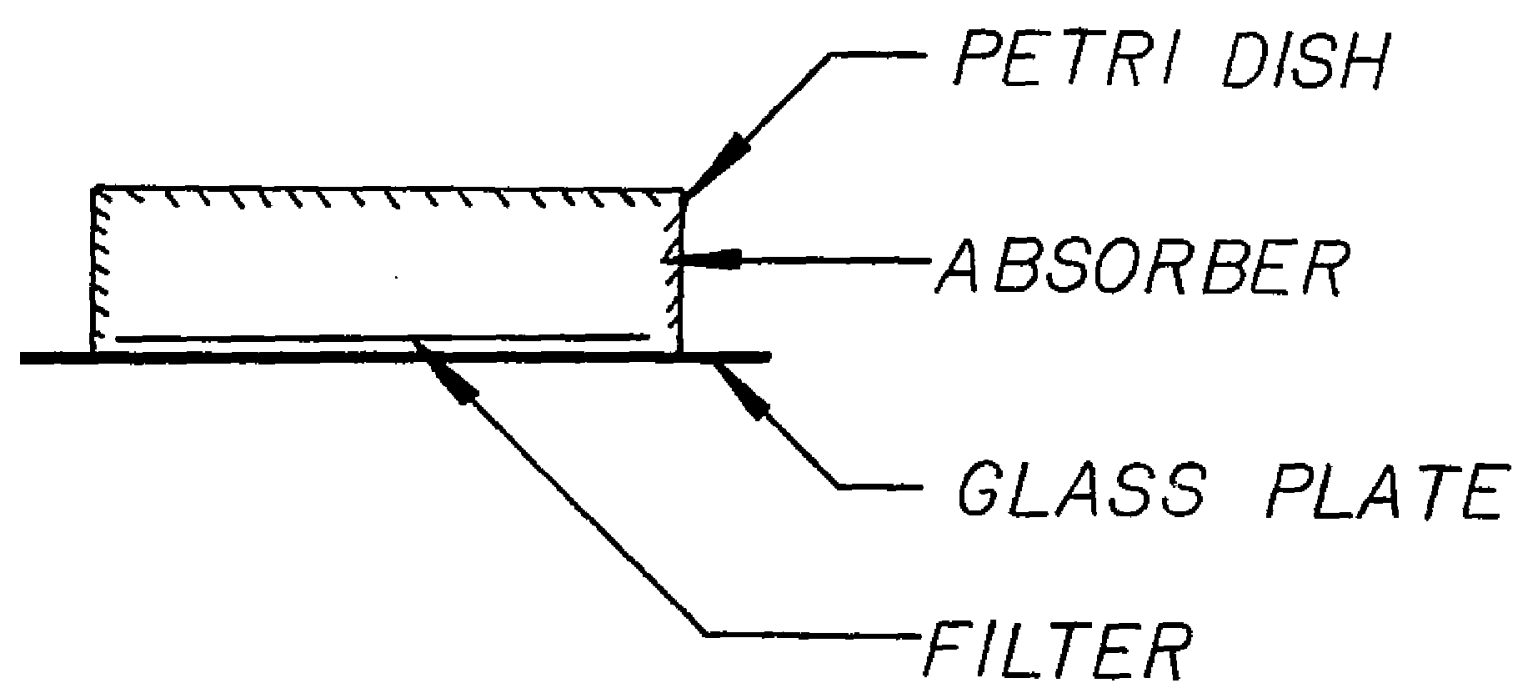


The samples were removed from the oven, and still covered, allowed to cool to room temperature. The petri dish and glass plate were then rinsed with 3 mililiters of water and the washings placed In a scintillation vial. Filter media were placed directly into the scintillation vial and the 3 milliliters of water were added. The petri dishes and the glass plates were then alr-drted, broken, and placed Into separate scintillation vials to determine mass balance data. The smaller dishes were stmply dropped into the vial and $3 \mathrm{ml}$ of water added. The scintillation vials were then filled with $17 \mathrm{ml}$ of the scintillation cockta1l and counted for $10 \mathrm{~min}$. or to $0.5 \%$ error, whichever came first.

Although the general procedure remained the same, the Individual experiments varied in regard to temperature, time and filter media. Specific changes such as filter media size and petri dish diameter will be noted in the discussion.

2. Results and Discussion

a. Microdiffusion from Glass Plates Before testing filter media for diffusion properties, a study of the microdiffusion apparatus was undertaken. A 63 mon piece of single strength window glass was used as the bottom and a 49 ID $x$ 14 Pyrex petri dish as the top (Figure 1). The chemical composition of the window glass approximated that of the glass fibex in the filters. Thus, apparatus design and diffusion conditions could be projected. The relative utility of polished and unpolished petri dish rims was studied.

Table I summarizes the inftial experiments. Quite unexpectedly, only $40 \%$ of the sulfurlc acid was found to diffuse from the untreated 
TABLE I

DIFFUSION AT $195^{\circ}$ FROM GLASS PLATE

USING POLISHED PETRI DISHES - EFFECT OF TIME

\begin{tabular}{|c|c|c|c|c|c|c|}
\hline 1 & $\begin{array}{c}\text { Reco } \\
2\end{array}$ & $\begin{array}{c}\text { ed on } \\
\text { ne (hr } \\
4\end{array}$ & $\begin{array}{l}\operatorname{trd} D \\
6\end{array}$ & Avg. & $\begin{array}{c}\text { Avg. } \\
\text { Mass } \\
\text { Balance }\end{array}$ & Treatment of Plate \\
\hline 38.0 & 43.0 & 39.0 & 43.9 & 41.0 & 96.6 & None \\
\hline- & - & 71.8 & 71.1 & 71.5 & 87.5 & $\begin{array}{l}\text { Conc. } \mathrm{H}_{2} \mathrm{SO}_{4} \text { Baked } \\
\text { at } 195^{\circ} \mathrm{C}\end{array}$ \\
\hline 47.6 & 48.0 & 50.2 & 54.3 & 50.0 & 97.8 & $\begin{array}{l}\text { Bolled in } 1: 1 \mathrm{H}_{2} \mathrm{SO}_{4} \\
\mathrm{H}_{2} \mathrm{O} \text { Rinse }\end{array}$ \\
\hline
\end{tabular}


glass. Even after placing several drops of concentrated sulfuric actd on the plate, heating in an oven at $195^{\circ}$ to evaporate the sulfuric actd and then placing splked sulfurtc acid on the treated area, only $71 \%$ diffused and the total amount recovered dropped to $87 \%$. As an alternate cholce, the glass plates were bolled in $1: 1$ sulfuric acid and rinsed In water. This was chosen as the preferred treatment for all of the glass plates. Figure 2 gives a summary of results of diffusion at temperatures of $100^{\circ}, 125^{\circ}, 150^{\circ}, 175^{\circ}$ and $195^{\circ}$ using polished petri dishes, and averaging the results of the 1,2, 4 and 6 hour runs for each temperature.

As can be seen, the best percentage of separation occurred at $125^{\circ}$. One possible reason for the decrease in diffusion as the temperature was increased from $125^{\circ}$ to $195^{\circ}$ could be the result of a tradeoff between vaporization vs. chemical reactivity. Referring to Table I, time had little effect on the amount diffused. The average range of separation for all temperatures between 1 and 6 hours was $6 \%$. Since vaporization (at or above $125^{\circ}$ ) is immediate, the added temperature apparently served only to increase the rate of attack of sulfuric acid toward the glass plate.

Figure 3 compares the 2-hour data at varlous temperatures for unpolished and polished petri dishes. The data for the polished petri dishes did not include data from the 1,4 or 6 -hour runs as Figure 2 does. Consequently, neglecting the points at $150^{\circ}$ for unpolished petrl dishes and at $125^{\circ}$ for pollshed petrf dishes, the results are linear Indicating that the unpolished are better than the polished petri dishes. The mass balance, however, for the unpolished petri dishes is 5 to $10 \%$ less than the pollshed petri dishes. In subsequent studies, only petri dishes with unpolished rims were used. 
FIGURE 2

MICRODIFFUSION OF SULFURIC ACID FROM

GLASS PLATES VS. TEMPERATURE 


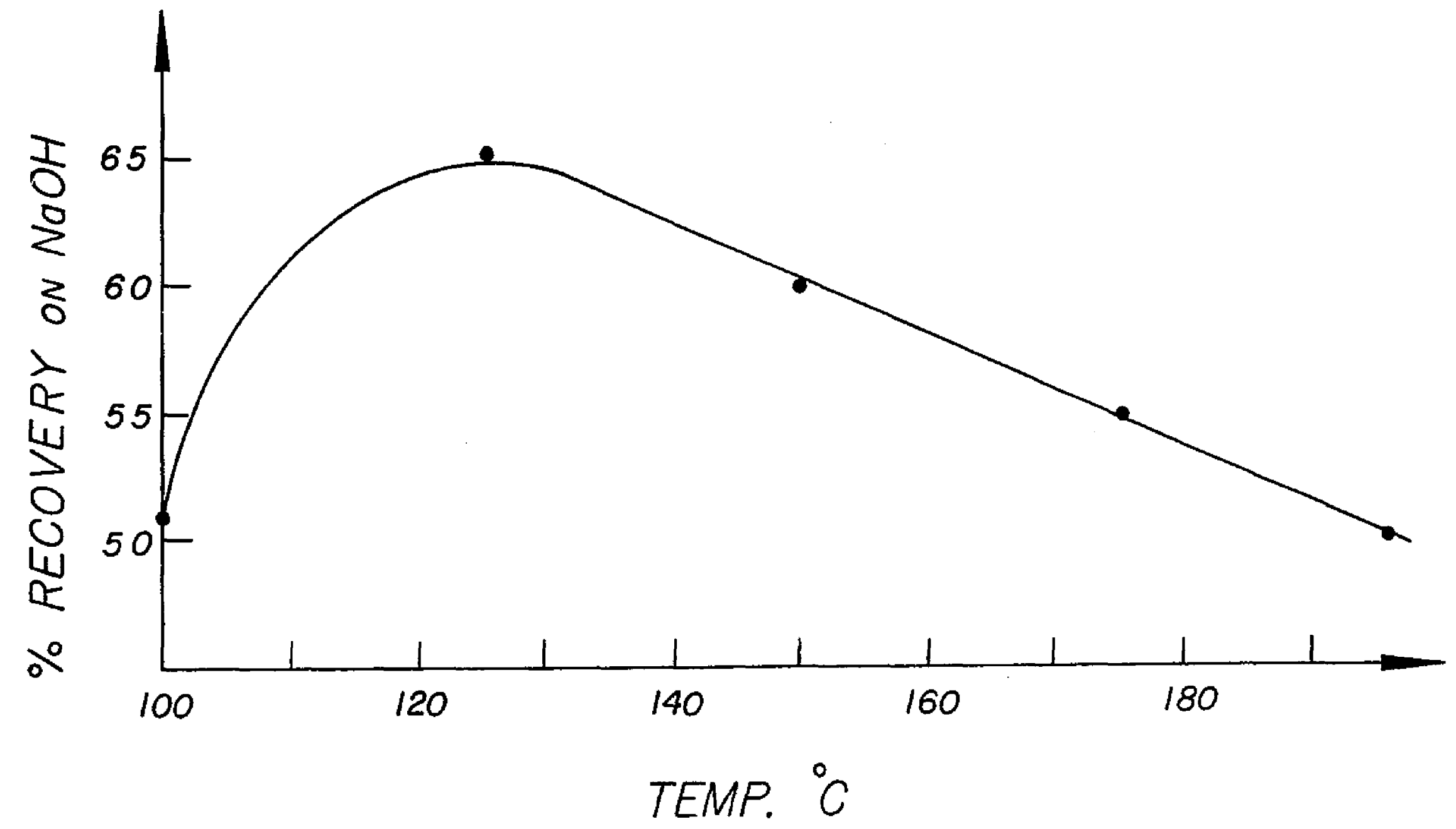




\section{F IGURE 3}

MICRODIFFUSION FROM POLISHED VS. UNPOLISHED PETRI DISHES 


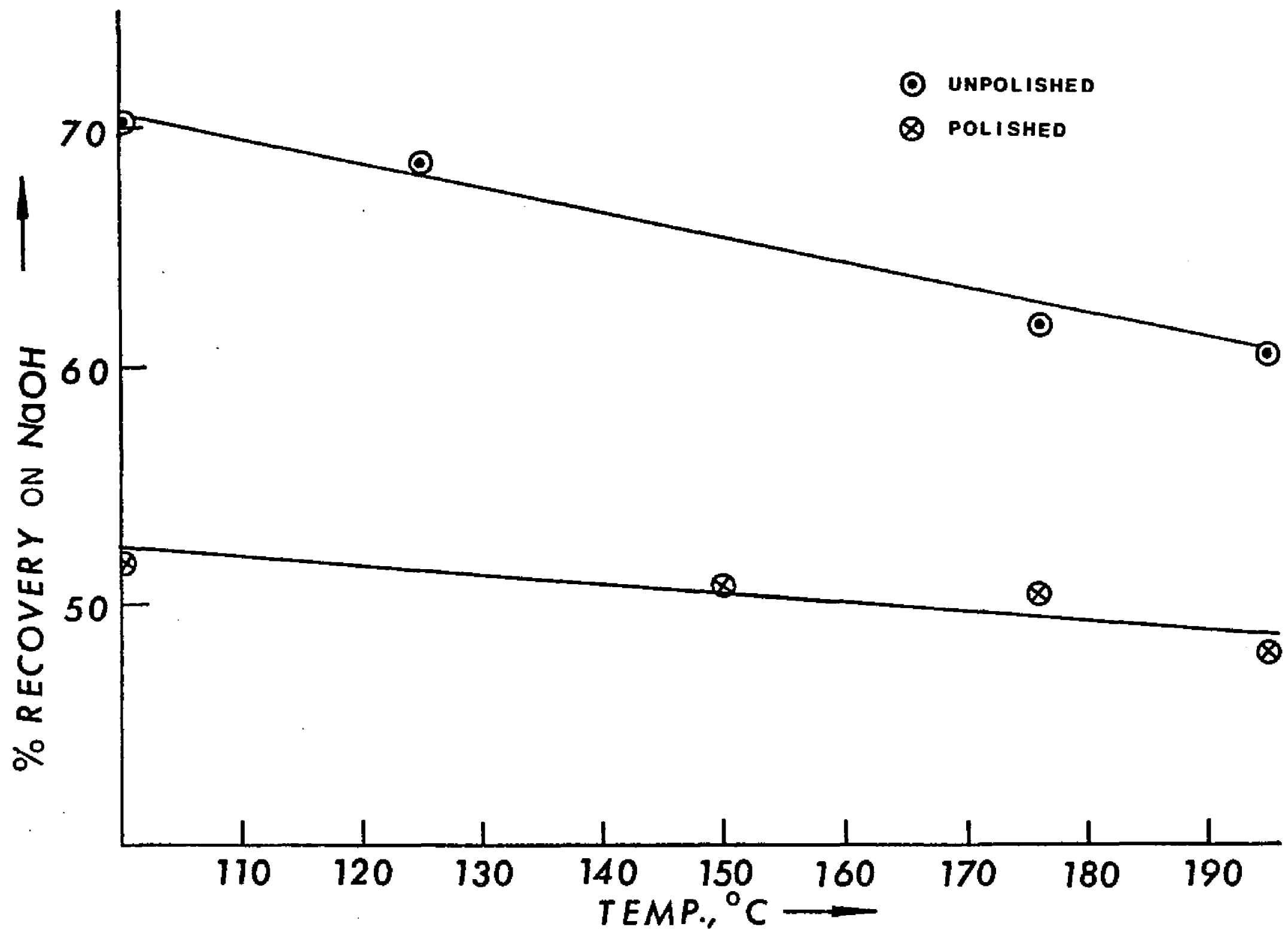




\section{b. Microdiffusion from Glass Fiber Filters}

After the design of the separation apparatus was optimized and some of the operating parameters were established, a study of glass fiber filters was initiated. Several surprising problems were disclosed. Experiments were made using 16 mm clrcular discs cut from an untreated $8 \times 10$-Inch sheet of Gelman A glass fiber filter. A 49 mm ID $x 14 \mathrm{~mm}$ petri dish and a glass plate were used as described in the Experimental Section. Ten microliters of spiked $1 \mu \mathrm{g} / \mu 1$ sulfuric acid were placed on the center of a disc and drfed. The first separations were attempted using a purged oven at $125^{\circ}$ for 6 hours. No diffusion occurred. Consequent $1 \mathrm{y}$, the filter was washed in various acids and the experiment was repeated, In all cases the results were negative.

Because $125^{\circ}$ was $70^{\circ}$ below the temperature at which Dubols, et al.,$^{37} \mathrm{~d}$ id the $1 \mathrm{r}$ work, the experiments were repeated at $195^{\circ}$. Again no diffusion was observed (Table II).

Barton and McAdie ${ }^{34}$ have published a method based on the pretreatment of the glass fiber with sulfuric actd, water, $80 \%$ isopropanol, and finally acetone. When their system was used, a small amount of diffusion was noted, but the results were insuffictent to warrant further study (Table II).

It was posstble that the affinity of the glass fiber for sulfurlc acid was such that the sulfuric acid did not diffuse. On the other hand, it was possible that a neutralization was occurring on the surface of the glass fibers. To test the latter hypothesis, $50 \mu l$ of a spiked $1 \mu g / \mu 1$ sulfuric actd solution were placed on three $16 \mathrm{~mm}$ discs of Gelman A glass fiber that had been treated by the Barton and McAdle method. The three discs were extracted with $3 \mathrm{ml}$ of warm distilled water. One milliliter of the extract was centrifuged to remove the 
TABLE II

RESULTS OF DIFFUSION FROM A 16 mm DISC OF GEIMAN A GLASS FIBER AT $195^{\circ}$ AFTER VARTOUS WASHES

\begin{tabular}{|c|c|c|}
\hline Treatment & TIme & $\begin{array}{l}\text { Activity } \\
\text { on NaOH }\end{array}$ \\
\hline Untreated & $6 \mathrm{hr}$ & $0.034 \%$ \\
\hline Bolled in $\mathrm{H}_{\mathrm{C}^{\circ}} \mathrm{O}$, blotted and dried at $80^{\circ} \mathrm{C}$ & $6 \mathrm{hr}$. & $0.051 \%$ \\
\hline $\begin{array}{l}\text { Boiled in } 1: 1 \mathrm{CH} z 0, \text { blotted and dried at } \\
80^{\circ} \mathrm{C}\end{array}$ & $6 \mathrm{hr}$. & $0.30 \%$ \\
\hline Botled in $1: 1 \mathrm{HCl}$ & $6 \mathrm{hr}$. & $0.32 \%$ \\
\hline $\begin{array}{l}\text { Botled in } 1: 1 \mathrm{H}_{3} \mathrm{PO}_{4} \text {, rinsed in } 1 \% \mathrm{H}_{3} \mathrm{PO}_{4} \text { and } \\
\text { dried at } 80^{\circ} \mathrm{C}\end{array}$ & $6 \mathrm{hr}$. & $1.0 \%$ \\
\hline $\begin{array}{l}\text { Soaked in } 20 \% \mathrm{H}_{2} \mathrm{SO}_{4} \text { for } 3 \text { days; bolled for } \\
10 \mathrm{~min} . ; \text { rinsed in } \mathrm{H}_{2} \mathrm{O} \text {, } 80 \% \text { isopropanol, } \\
\text { and acetone; then air dried. }\end{array}$ & $6 \mathrm{hr}$. & $3.5 \%$ \\
\hline $\begin{array}{l}\text { Soaked in } 20 \% \mathrm{H}_{2} \mathrm{SO}_{4} \text { for } 3 \text { days; bolled for } \\
10 \mathrm{~min} . ; \text { rinsed in } \mathrm{H}_{2} \mathrm{O}, 80 \% \text { isopropanol, } \\
\text { and acetone; then air dried. }\end{array}$ & $12 \mathrm{hr}$ & $4.0 \%$ \\
\hline
\end{tabular}


solids. Fifty microliters of this centrifuged extract were then diffused from a treated glass plate using an unpolished $49 \mathrm{~mm} \times 14 \mathrm{~mm}$ petr1 dish for 6 hours at $125^{\circ}$. As previously shown (Figure 2), approximately $65 \%$ of the sample should have diffused; however, no diffuston occurred.

The lack of diffusion could be attributed to the neutralization of the sulfuric actd by the glass fiber filter. In order to measure the glass fiber filter's capacity to neutralize the sulfuric actd, $50 \mu \mathrm{l}$ aliquots of an unsptked $1 \mu \mathrm{g} / \mu \mathrm{l}$ of sulfurle actd were placed on the untreated $16 \mathrm{~mm}$ glass fiber filter disc and dried. Ten microliters of the spiked $I \mu g / \mu l$ sulfuric acld solution were then placed on the disc, dried and diffused.

Even $200 \mu \mathrm{g}$ of sulfuric acid did not neutralize the available alkaline sites. A possible explanation for these results is the penetration ability of the sulfuric acid solution to the alkaline sites. It must be remembered that neutralization products (sodium chloride, sodium sulfate, sodium phosphate or sodium acetate), dependIng on what acid is used to pre-treat the filter, are soluble in water. A solution of sulfuric actd could dissolve and expose new alkaline sites underneath the neutralized layer. Furthermore, solutions tend to spread over the glass fibers in a thin film. Consequently, more of the sulfuric acid solution is exposed to the alkaline sites. On the other hand, the lack of wetting power of concentrated acids prevents the natural sulfuric acid aerosol from penetrating to the alkaline sites under the neutralized layer. Rather they tend to coalesce into droplets lewing only the bottom edges exposed to the filter surface. 
It is possible, therefore, that the flrst few hours of a high volume sampling serves to neutralize most of the alkaline sttes. Sulfurtc acid aerosol actd then can sit on a neutralized layer and for the above reasons not penetrate to new alkaline sites. Dubols, et al., 38 have also used this reasoning to explain why the concentration of sulfates in air depends on the sampling volume.

Before turning to other types of filters, investigations were made regarding the volatility of ammontum sulfate and the use of 1sopropanol as a selective solvent for sulfurlc acid.

Dubols, et $\underline{\text { al. }},,^{37}$ mentioned that ammonium sulfate could be used as a standard for diffusion at $195^{\circ}$. Consequently, this spectes would be an interference if it were present in an atr sample. A thermal gravimetric analysis was made of a finely ground reagent grade ammonium sulfate In nitrogen atmosphere. Decomposition started at $250^{\circ}$ and a second slope occurred after $340^{\circ}$. Erdey, et al. ${ }^{39}$ reported similar results and also included a differential themal analys1s. They reported the following reactions at the indicated temperature ranges:

$$
\begin{aligned}
& \left(\mathrm{NH}_{4}\right)_{2} \mathrm{SO}_{4} \stackrel{250-350^{\circ}}{\longrightarrow} \mathrm{NH}_{4} \mathrm{HSO}_{4}+\mathrm{NH}_{3} \\
& \mathrm{NH}_{4} \mathrm{HSO}_{4} \stackrel{350-450^{\circ}}{\longrightarrow} \mathrm{NH}_{3}+\mathrm{H}_{2} \mathrm{SO}_{4}
\end{aligned}
$$

Using a scan rate of $5 \% / \mathrm{min}$. no loss of sample was observed until $250^{\circ}$. An 1sothermal TGA run at $175^{\circ}$ and $205^{\circ}$ showed a $1.8 \%$ and 8.2\% welght loss for a 3 -hour period. Assuming this welght loss to be IInear, a loss of $9.6 \%$ and $43.7 \%$ at $175^{\circ}$ and $205^{\circ}$, respectively, for overnight ( 16 hours) heating would be expected. Proper cholce of time and temperature can minimize the effect of ammonium sulfate as an interferant. 
Fina1ly, $10 \mu 1$ of a spiked $1 \mu g / \mu 1$ solution of sulfuric actd were placed on two $16 \mathrm{~mm}$ discs of glass fiber and dried at $80^{\circ}$ for 5 min. The discs were placed in separate scintillation vials, and 3 mls of 1sopropanol added. After shaking the vials for several minutes, the isopropanol was poured off into another vial. The extract, filters and standards were counted and it was found that $50 \%$ of the activity was in the extract. From our previous results we belleved the $10 \mu \mathrm{g}$ of sulfuric actd to be completely neutralized and consequently, the 1sopropanol in this crude extraction removed $50 \%$ of the sulfurlc acid as a salt. It appears that at this concentration, Isopropanol is not a selective solvent for sulfuric actd.

\section{c. Microdiffusion from other Filter Media}

Several other filter papers and membranes were tested. Included in the group were: Nucleopore, Whatman 41, Solvinert, Spectrogram Corporation 47-XA3 Poco Graphite filter (experimental) and Mitex (Teflon). The glass apparatus shown in Figure 1 was also used in these experiments. Nucleopore was tested at $100^{\circ}$ for 6 hours with no diffusion observed. Both Whatman 41 and Solvinert were run at $125^{\circ}$ for 6 hours. Whatman 41 exhibited no diffusion while the Solvinert had $13.5 \%$ diffusion. In both cases, $10 \mu g$ samples of optked sulfuric actd were used. Whatman 41 and Nucleopore both had a 49 mm ID petri dish as the absorbIng dish while a $13 \mathrm{~mm} \mathrm{ID} \times 5 \mathrm{~mm}$ dish was used for the Solvinert study. The Poco graphite filter was tried next. The filters were 47 in dfameter, brittle yet slightly flextble. Using a stainless steel cork borer mounted on a drill press, 8 mm diameter discs were cut from the $47 \mathrm{~mm}$ disc. Using the standard $49 \mathrm{~mm}$ ID petri dish and glass 
plate, $10 \mu 1$ of the $1 \mu g / \mu 1$ splked sulfuric acid solution were placed on the filter disc. The water was driven off at $80^{\circ}$ for $10 \mathrm{~min}$, and then diffused at $195^{\circ}$ for 6 hours. The results were encouragling as only $1.6 \%$ was left on the filter and $60 \%$ microdiffused to the sodium hydroxide. Another temperature was tried (150\%/6 hrs.) but the amount of sulfuric acid left on the filter increased to $9.2 \%$ while the microdiffused portion was $57 \%$. A time plot of $1,2,4$ and 6 hours at $195^{\circ}$ was run and it was found that 3 hours was sufficient to reduce the amount left on the filter to $\sim 3 \%$.

In dolng a mass balance on the above systems, it was found that $30 \%$ of the activity was left on the glass plate. Since the filter only covered a small part of the glass plate under the petrl dish, the $49 \mathrm{~mm}$ ID petri dish was replaced with a $13 \mathrm{~mm}$ and $9 \mathrm{~mm}$ ID dish, both approximately $10 \mathrm{~mm}$ high. The experiment $\left(195^{\circ} / 3 \mathrm{hrs}\right.$.) was repeated with the $8 \operatorname{mm}$ graphite filter. The results (Table III) showed that the amount of sulfuric acid found on the glass plate was directly related to the area of the exposed glass plate beneath the petri dish. In order to minimize the loss of sulfuric actd to the glass plate, the ID of the petri dish should nearly match the diameter of the filter disc used.

At first these results seemed surprising, but they can be understood in terms of a diffusion controlled reaction. The sulfuric acid vaporizes uniformly throughout the diffusion system. The filter is tnert and only minimal amounts rematn there while the soft glass plate and the sodium hydroxide offer excellent neutralization stes. Consequently, after subtracting the area covered by the filter, the sulfuric acid uniformly spreads itself about the inside area. As will 
TABLE III

AMOUNT OF SULFURIC ACID FOUND ON GLASS PIAATE FOR DIFEERENT SIZE PETRI DISHES AND $8 \mathrm{~mm}$ FILTER

\begin{tabular}{ccc}
$\begin{array}{c}\text { ID of } \\
\text { Petri DLsh }\end{array}$ & $\begin{array}{c}\text { Exposed Glass Plate as } \\
\text { \% of Total Inside Area }\end{array}$ & $\begin{array}{c}\text { \% Sulfuric Acid } \\
\text { on Glass Plate }\end{array}$ \\
\hline $49 \mathrm{~mm}$ & 31.0 & 31.1 \\
$13 \mathrm{~mm}$ & 11.4 & 12.9 \\
$9 \mathrm{~mm}$ & 3.1 & 5.1 \\
\hline
\end{tabular}


be seen In Chapter $V$, it will be necessary to trap the sulfurtic acid on the absorber, so in this and all future work the entire inside of the. petri dish was coated with an absorber.

The Mitex Teflon filters were tested next. In this case a. 13 III $\times 5$ mm dish was used. The 47 dLameter disc was cut into quarters and $10 \mu 1$ of a spiked $1 \mu g / \mu 1$ solution of sulfuric acid was placed on the filter. The sodlum hydroxide coated dish was centered over the dried solution and then diffused.

The first temperature tried was $125^{\circ}$ and heating was carried out for 3 and 6 hours with $79 \%$ and $85 \%$ of the sulfurlc acid applted respectively, diffused to the sodium hydroxide with approximately $9 \%$ left on the fllter. Under the same arrangement the filters were heated at $195^{\circ}$ for 3 hours. In this case, $82 \%$ microdiffused while $6 \%$ remained on the filter. Both temperatures seemed to work equally well so it was dectied to xun a calibration curve from 0.1 to $50 \mathrm{\mu g}$ sulfurtc actd for the Mitex filter at $125^{\circ}$ for 6 hours and at $195^{\circ}$ for 3 hours. Concurrently, a similar calibration curve was run for the Poco graphite filter at $195^{\circ}$ for 3 hours. The results of these studies are shown in FIgures 4 and 5 .

The graphs show a distinct cut-off for the lower 1 fmit of diffusion. For the system of $13 \mathrm{~mm}$ ID dishes, the value was $10 \mathrm{Hg}$. At first, it was belleved that a neutralization was again affecting the system. It is, however, unlikely that two unrelated filter materials would show the same neutralization characterlatics. Neutralization is also unlikely as increasing the temperature from $125^{\circ}$ to $195^{\circ}$ increased the amount of sulfurtc actd microdiffused at $5 \mu \mathrm{g}$ from 3 to $19 \%$ for the Mitex filter (Figure 5). Later experiments presented in Chapter $V$ will clarify the situation further. 
FIGURE 4

MICRODIFFUSTON FROM POCO GRAPHITE FILTERS

FOR 3 HOURS AT $195^{\circ}$ 


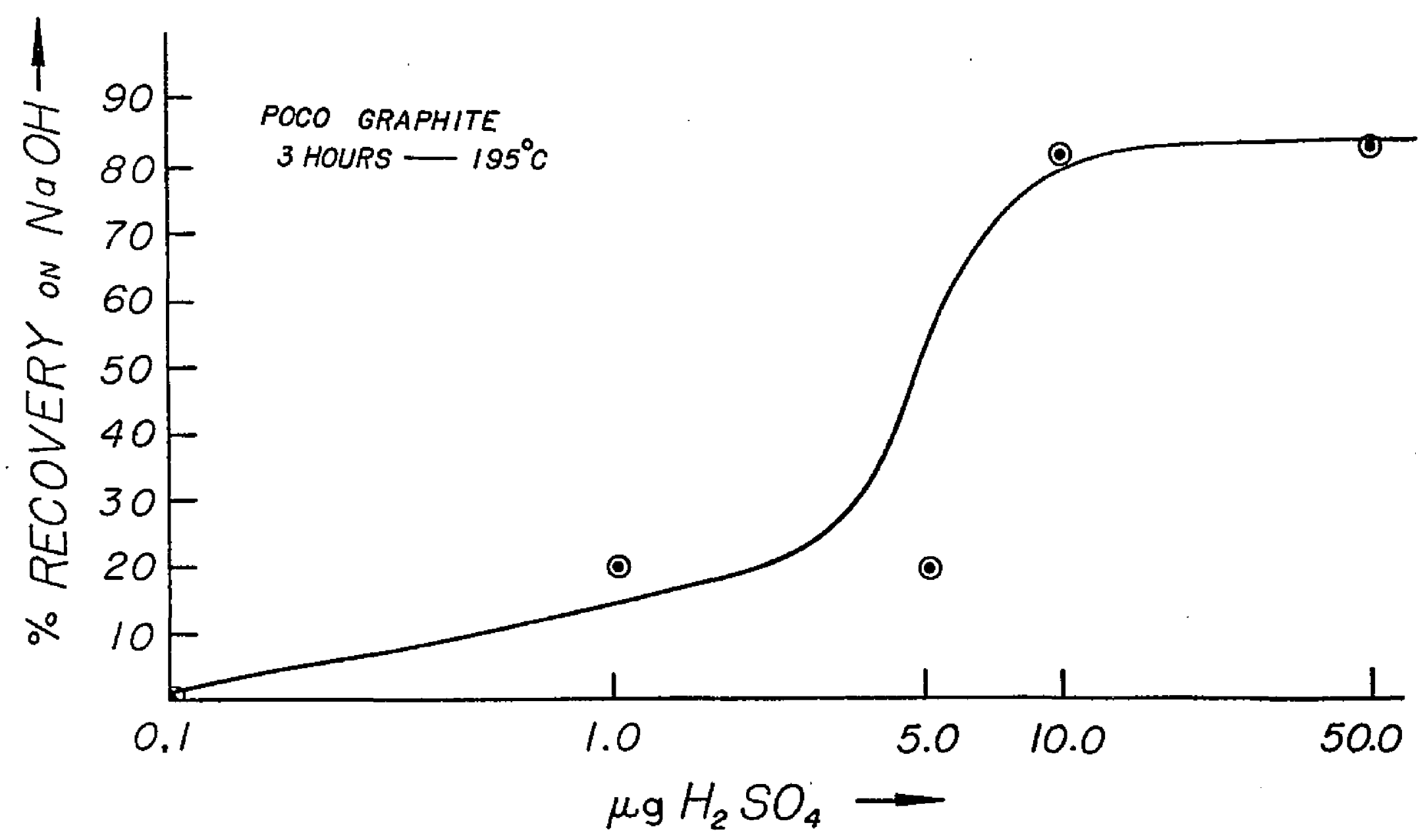

w 
FIGURE 5

MICRODIFFUS ION FROM MITEX TEFLON FILTERS

FOR 3 HOURS AT $195^{\circ}$ (A) AND FOR 6 HOURS AT $125^{\circ}$ (O) 


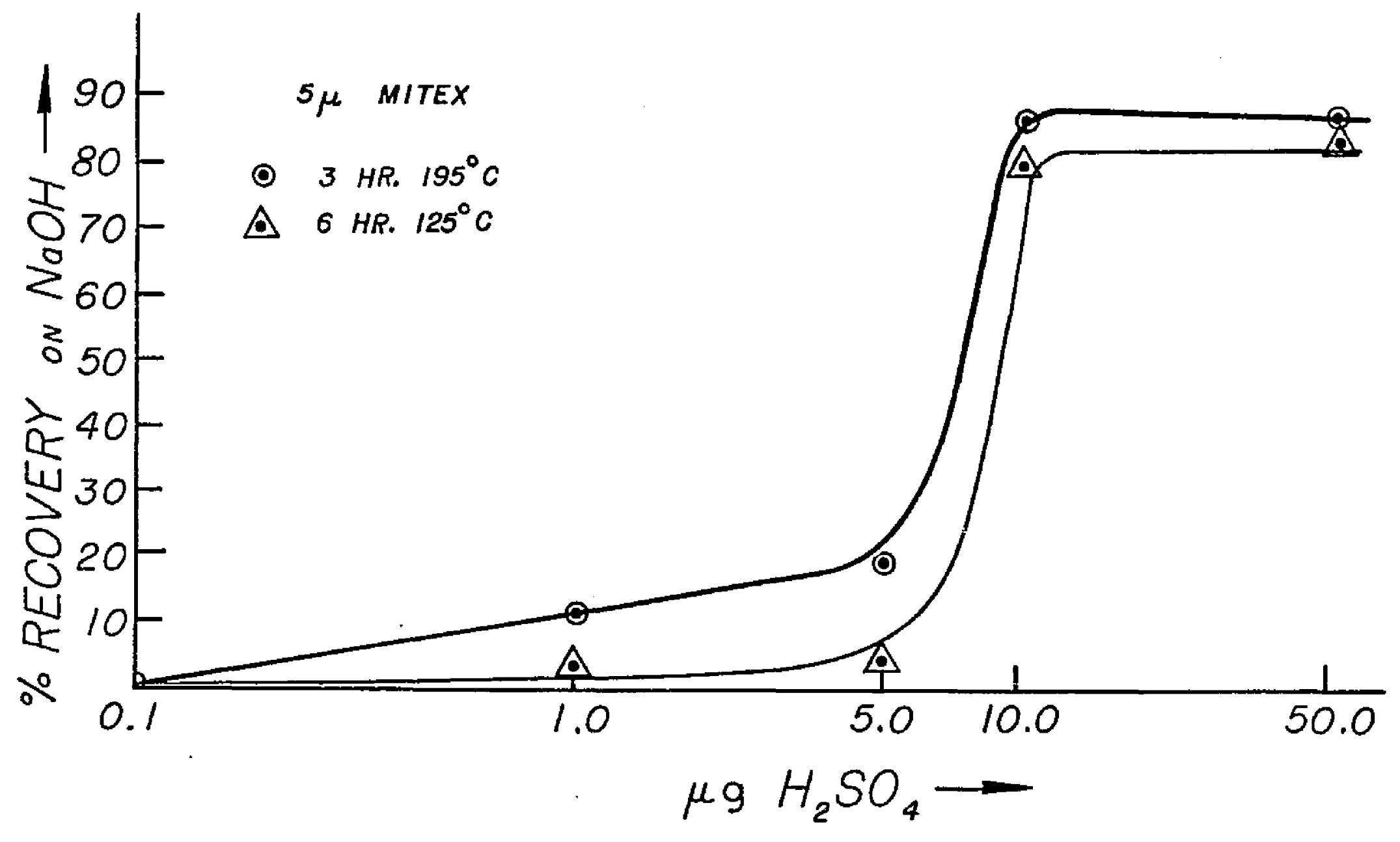




\section{Conclusions}

From these investigations the following observations can be made:

1. Since the sulfuric acid diffuses throughout the entire inside of the apparatus, the microdiffusion apparatus should be modifled to a system in which the absorbing substance covers the entire Inside surface except that area covered by the filters.

2. The Inner diameter of the cover dish should exactly (within $1 \mathrm{~mm}$ ) match the diameter of the filter media.

3. Glass fiber filters should not be used as a sulfuric acid sampling medium.

4. Suttable filters for collecting sulfuric acid aerosol can be made of pure Teflon or graphite.

5. Isopropanol should not be considered to be a selective solvent for sulfuric acid.

The application of these results awalted only a proper analytical fintsh. The development of this new approach to sulfate analysis w11 be discussed in the following chapter. 
CHAPTER IV. REDUCTION OF SULFATE TO SULFUR DIOXIDE

VIA THERMAL DEGRADATION OF PERIMIDYLAMMONIUM SULFATE

\section{A. Previous Attempts at Sulfate Reduction}

Once a separation procedure had been worked out, the next step in the determination of sulfurlc acld aerosol was the development of a sultable analytical finish for sulfate. Since both the West-Gaeke 40 and the flame photometric 41 approach offered specific and sensitive methods for measuring sulfur dioxide, the catalytic reduction of sulfate to sulfur dioxide appeared to be an attractive approach. A search of the literature showed that several investigators had attempted to reduce sulfates or oxidize sulfur to sulfur dioxide.

Heslinga, In $1925^{42}$ determined sulfur by burning samples in a quartz tube and completing the combustion by passing the gases over hot quartz chips. The sulfur gases were absorbed in a hydrogen peroxide solution, and the sulfur titrated as sulfuric acld. Other investigators refined the apparatus of Heslinga.43-45

Kristen ${ }^{48}$ volatilized residual sulfur from the ash of certain blological matertals by heating the sample in a combustion tube with vanadtum pentoxide. Hagernan and Faust 47 used vanadium pentoxide fusion to measure sulfur in refractory materials, while Larsen, et a1.,48 employed the same approach to analyze uxanfum trioxide, sodium zirconfum fluoride and hydrofluortc acid. The interesting part of Larsen's work was the reduction of the initially produced sulfur trioxide over copper at $950^{\circ}$. The sulfur dloxide produced was trapped in tetrachloromercurate(II) and measured by the West-Gaeke procedure. 
The measurement of sulfuric actd aerosol was attempted by Scaringelli and Rehme. ${ }^{49}$ Sulfuric actd (vaporized from glass fiber fliters) or sulfur trloxide (produced when copper lmpactors were heated) was reduced over copper at $500^{\circ}$. Aside from its drawbacks in measuring sulfuric acid aerosol (see Chapter V), the method required complicated equipment and extremely tedious procedures. Except for sulfurtc actd, ammonium sulfate, ammonium hydrogen sulfate and copper sulfate, 49 the remaining sulfates decomposed above $400^{\circ}$.

For a flexible sulfate determination, a system was sought which would not require drastic heating for reduction. A search was Initiated for an organic anine which would both precipitate sulfate and upon heating, promote the reduction of sulfate to sulfur dioxide. In early 1970, Stephen ${ }^{31}$ proposed a new nephelometric sulfate determination based on the prectpitation of sulfate by perimidy lammontum chloride (PDA-CI). The solubility of the precipitated perimidylammonium sulfate $\left[(\mathrm{PDA})_{2} \mathrm{SO}_{4}\right]$ is somewhat less than that of bartum sulfate. This low solubility made (PDA) ${ }_{2} \mathrm{SO}_{4}$ the most insoluble organic anine sulfate known. Mcclure 50 synthesized stephen's reagent via cyanogen bromide and 1,8-diaminonaphthalene, producing the bromide salt which was used in all of our studies.

\section{Experimental}

\section{a. Reagents}

Perimidylammontum Bromide, $0.5 \%$ - Fifty milligrams of PDA-Br synthesized according to McClure50 and recrystallized twice from methanol was added to $10 \mathrm{ml}$ of distilled water. Th1s solution was made fresh daily. 
Potassium Sulfate Stock Solution - 1.81 grams of freshly dried reagent grade potasstum sulfate were added to 1 liter of distilled water to give a solution $1 \mu g / \mu 1$ as sulfate. Solutions containing $0.1 \mu g / \mu 1$ of sulfate were made up by dilution of the stock solution.

Sodium Tetrach Loromercurate(II), $0.1 \mathrm{M}$ - Reagent grade mercury(II) chloride ( $27.2 \mathrm{~g}$ ) and reagent grade sodium chloride ( $11.2 \mathrm{~g}$ ) were dissolved and diluted with distilled water.

Formaldehyde Solution, $0.2 \%-0.5 \mathrm{ml}$ of $40 \%$ formaldehyde solution was added to $100 \mathrm{ml}$ of distilled water. This solution was made fresh dally.

Pararosaniline Hyđrochloride - $0.64 \mathrm{~g}$ of reagent grade pararosaniline hydrochlorlde was added to $240 \mathrm{ml}$ of concentrated $\mathrm{HCl}$, and diluted to 1 liter with distilled water. Twenty-five $\mathrm{ml}$ of this solution were diluted to $100 \mathrm{ml}$ with distilled water to provide the working solution.

Nitrogen - Pre-purified.

Oxygen - Pre-purified.

\section{b. Apparatus}

Spectrophotometer - Beckman DB.

Sulfur DLoxide Permeation Tubes - Six mm ID $x 120 \mathrm{~mm}$ Teflon tubes containing liquid sulfur dloxide and stoppered at both ends with Teflon plugs were placed in a controlled temperature cell. At constant temperature the rate of permeation of sulfur dioxide through the Tefion tube was also constant. The permeation rate was determined by repeated weighing of the tubes over an extended time pertod. In this case the permeation rate of sulfur dioxide was found to be $10.07 \mu \mathrm{g} / \mathrm{min}$. 
Pyrolysis Oven - A Sargent microcombustion furnace (s-21580) was modified to accept a 25 to 33 mm OD quartz tube. The original heating colls were retained, but a No. 50122-Type 1708-KSP LIndburg cylindrical heating block was added to the top hinge of the oven. The Lindburg was controlled by a separate Variac.

Combustion Train - At' one end of a $25 \mathrm{~mm}$ OD $\times 65$ um quartz tube a 33 m oD $34 / 45$ female ground glass joint was attached. The other end of this $25 \mathrm{~mm}$ OD quartz tube was fitted with an $11 \mathrm{~mm}$ OD $\mathrm{x}$ $60 \mathrm{~mm} 18 / 9$ Vycor male ball joint. A bubbler was connected to the quartz tube vla 6 mm ID Teflon tubing, glass tubing and a Pyrex $18 / 9$ female ball joint (see Figures 6 and 7 ).

Injector System - A 34/45 Pyrex male ground glass jolnt was fitted on its center line with a $12 \mathrm{~mm}$ OD $x 30 \mathrm{~mm}$ Pyrex tube. This tube was blown with an inside depression half-way down its length enabling it to accept a Viton high temperature 0-ring (11 $\mathrm{mm}$ oD). A $9.5 \mathrm{~mm}$ oD Teflon sleeve with a 6.5 center tap was inserted into the 12 OD tube. A 6 mm oD $\times 80$ mm quartz rod with a fork designed to hold a $15 \mathrm{~mm}$ OD dish at one end was Inserted through the Teflon sleeve. By means of another Viton 0-ring ( $6 \mathrm{~mm}$ ID) and Tefion washer, the system was made air-tight. Finally, at $90^{\circ}$ to the center line of the $34 / 45$ male joint, a $10 \mathrm{~mm}$ piece of $7 \mathrm{~mm}$ oD Pyrex tubing was added to the side of the joint to act as an inlet/outlet port (see Figure 6). Flame Photometric Detector - A Bendix Model 8300 and a Meloy SA-102 Total Sulfur Analyzer were used as $\mathrm{SO}_{2}$ monttors. Plpets - Solutions were pipetted with a 10 or $50 \mu \mathrm{g}$ Eppendorf pipet. 
FIGURE 6

COMBUSTION TUBE AND INJECTOR 


\section{COMBUSTION TUBE \& INJECTOR}

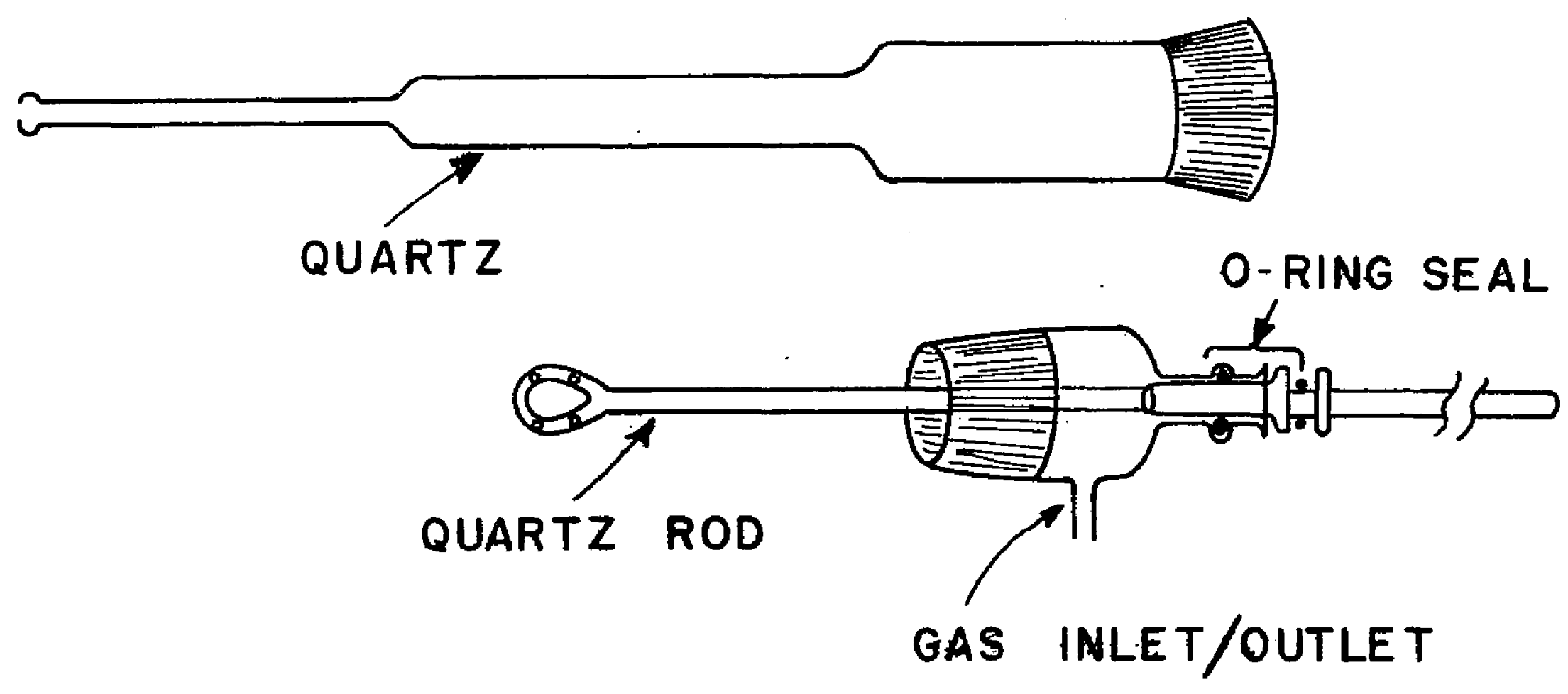


FIGURE 7

COMBUSTION TRAIN 


\section{COMBUSTION TRAIN}

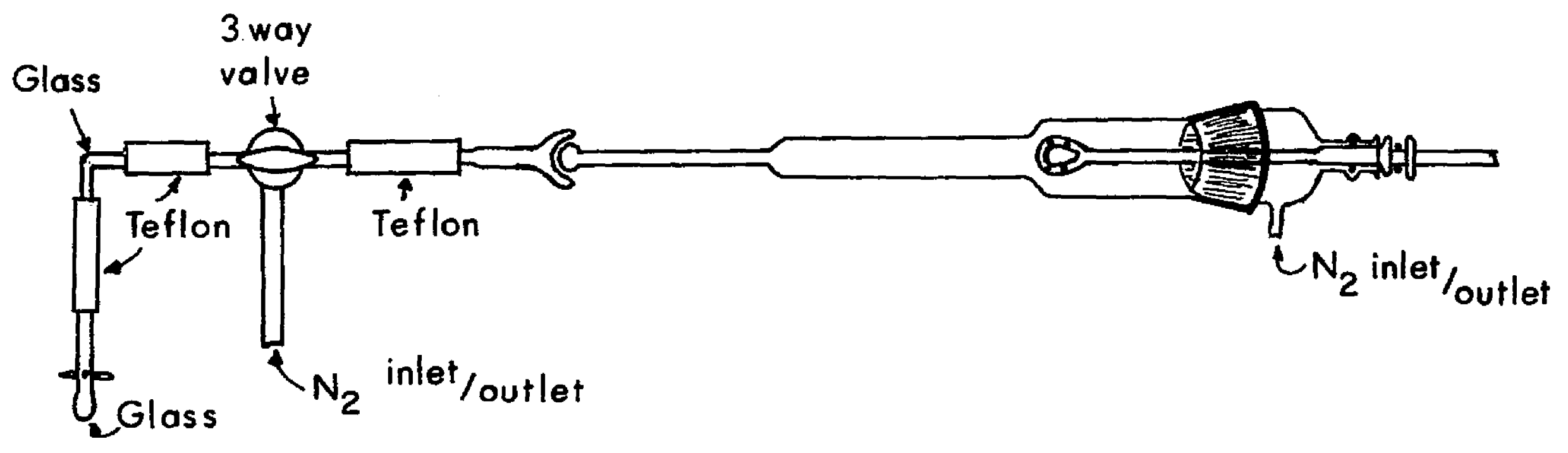


Glass Dishes - Soft glass vials, $15 \mathrm{~mm}$ OD $\times 120 \mathrm{~mm}$, were cut $15 \mathrm{~mm}$ from the bottom to provide dishes for the precipitation of standard sulfate solutions.

Thermogravimetric Analyzer and Differential Scanning Calorimeter - Dupont 950 TGA and DSC was used.

Flowmeters - Lab-crest rotameters of approprlate ranges were used. These were accurate to $\pm 2 \%$ of full scale.

c. Procedure

Samples of sulfate were placed in $15 \mathrm{~mm}$ OD $x 15 \mathrm{~mm}$ glass dishes, and $200 \mu 1$ of a $0.5 \% \mathrm{PDA}-\mathrm{Br}$ water solution were added. A silky white precipitate was immediately formed. After precipitation was complete (approximately 10 minutes), the dishes were placed in an oven set at $80^{\circ}$ to evaporate the excess 11quid. With the pyrolysis oven set at $500^{\circ}$, the nitrogen flowrate at $500 \mathrm{ml} / \mathrm{min}$, and $10 \mathrm{ml}$ of $0.1 \mathrm{M}$ tetrachloromercurate(II) in the bubbler, the samples were ready to be pyrolyzed.

By proper manipulation (see Figure 7) of the 4-way valves and a 3-way stopcock, the nitrogen flow was fed through the Injector, past the hot zone, and into the West-Gaeke trap (pyrolysis mode), or the flow was reversed so the nitrogen would pass through the 3-way stopcock, back through the oven, and out the injector male joint (backflush mode). This flow system allowed the oven to operate continually while a nitrogen blanket was maintained in the quartz combustion tube.

A typical pyrolysis cycle would be:

1. Pull the injector rod out of the hot zone.

2. Remove the tetrachloromercurate(II) solution from the bubblex. 
3. Reverse the nftrogen isow the backflush mode.

4. Remove the entire injector system at the $34 / 45$ joint.

5. Place a fresh sample on the injector fork.

6. Replace the injector in the $34 / 45$ joint.

7. Place the nit rogen flow in the pyrolysis mode.

8. Replace the tetrachloromercurate(II) solution in the bub-

bler.

9. Slide the injector rod into the center of the oven.

10. Heat the sample for 2.5 minutes.

This entire cycle, including replacing the West-Gaeke trap, would take approximately 3.5 minutes.

After several pyrolysis runs, the quartz tube immediately outside of the oven on the bubbler side of the oven collected a small amount of organic debris. The Teflon and glass tubing leading to the bubbler were also coated with this material. The sulfur dioxide evolved during the pyrolysis was not adsorbed on this material, but as a precaution the quartz tube was periodically cleaned. The quartz tube was disconnected from the system at the ball joint, and retracted into the oven. At the same time oxygen was fed fnto the quartz tube, and the temperature was raised to $700^{\circ}$. While the quartz tube was being heated, the rest of the combustion train was rinsed with acetone and allowed to air dry. Within 10 minutes, the combustion train was ready for use.

B. Results and Dlscussion

In order to check the efficlency of the reduction of sulfate to sulfur dloxide, a standard curve of net absorbance versug micrograms of sulfur dioxtde was established for the West-Gaeke procedure. A dry 
alr stream was passed through the thermostated cell containing the sulfur dioxide permeation tube, and was scrubbed in a bubbler containing $10 \mathrm{ml}$ of $0.1 \mathrm{M}$ tetrachloromercurate(II). The contents of the bubbler were diluted to $250 \mathrm{~mL}$ with $0.1 \mathrm{M}$ tetrachloromercurate(II) to provide a stock solution containing $2.5 \mathrm{\mu g}$ sulfur dioxide in each milifiter. Using this stock solution, a standard curve was plotted from 0 to $20 \mathrm{\mu g}$ of sulfur dtoxtde.

Following McClure's ${ }^{50}$ procedure, a sufficient quantity of PDA-Br, though light and molsture sensltive, could be stored up to a month before an Increase in the blank values was noted. Solutions of PDA-Br were normally made fresh daily, but if kept in an amber bottle, they could be used for a week.

A $0.5 \%$ solution of $\mathrm{PDA}-\mathrm{Br}$ was made as suggested by stephen ${ }^{31}$ and was mixed with small amounts of sulfate in a test tube. The precipitate was collected by centrifugation, and was washed several times In methanol to remove the excess $\mathrm{PDA}-\mathrm{Br}$ and water. After the (PDA) $\mathrm{S}^{\mathrm{SO}_{4}}$ was drted in an oven at $80^{\circ}$, a Thermogravimetric Analysis and a Differentlal Scanning Calorimeter studies were conducted. Flgure 8 shows the results of the DSC and TGA. The DSC showed an endothermic peak at $450^{\circ}$, while the TGA confirmed that this peak was not just a phase change, but a reaction with the formation of a new product. Because the new product was volatile, an exact value for the molecular weight loss could not be determined. Several TGA's were run, and the results Indicated that a molecular weight loss of 115 occurred. From this datum 1t was not posalble to determine directly whether sulfur dioxide or sulfur trioxide was being formed. However, the West-Gaeke procedure is specific for sulfur dioxide, and thus if formed it could be measured. 
FIGURE 8

DIFFERENTIAL THERMAL ANALYSIS AND DIFFERENTIAL SCANNING CALORTMETER OF (PDA) ${ }_{2} \mathrm{SO}_{4}$ 

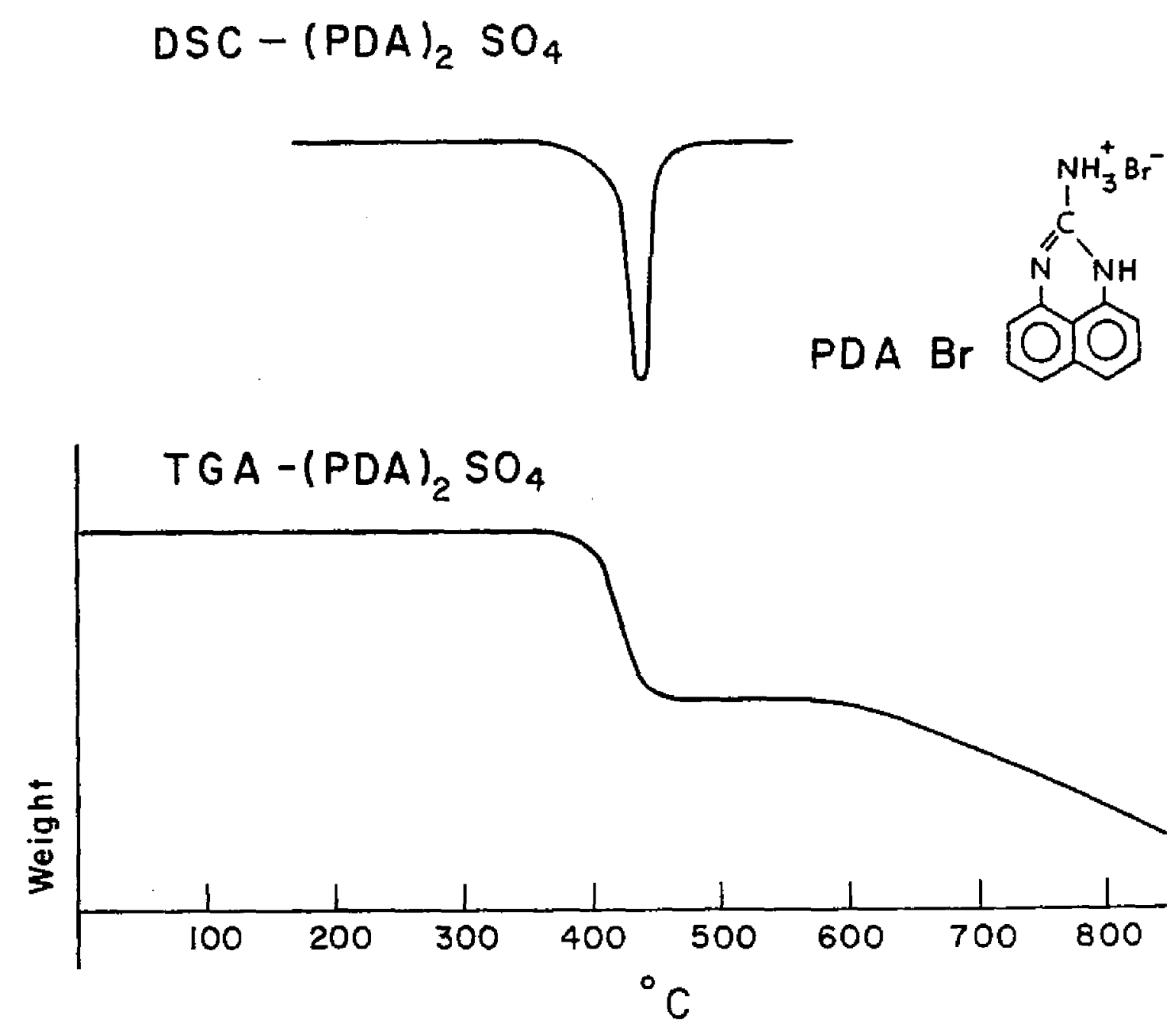
The pyrolysis products were tested for evidence of sulfur dioxide formation by pyrolyzing samples of (PDA) $\mathrm{SO}_{4}$ in the quartz combustion tube (Figure 6). The effluent gases were bubbled through $10 \mathrm{ml}$ of $0.1 \mathrm{M}$ tetrachloromercurate(II), and the color was developed by addition of formaldehyde and p-rosantiline. The appearance of a deep violet-purple color, when (PDA) ${ }_{2} \mathrm{SO}_{4}$ was pyrolyzed and the absence of color when PDA-Br was pyrolyzed, confixmed the reduction of sulfate to sulfur dioxide (Figure 9).

Stephen reported an extensfve survey of PDA-Br reactions with other antons, and concluded that a 10-fold excess of most common anions.would not interfere with the precipitation of $(\mathrm{PDA})_{2} \mathrm{SO}_{4}$. This, however, did not preclude the posstbility that various salts of PDA exhlbit a blank when pyrolyzed. Ten micrograms each of phosphate, carbonate and nitrate were placed in separate dishes, and $200 \mu 1$ of $0.5 \% \mathrm{PDA}-\mathrm{Br}$ were added. After the excess water was evaporated, these dishes were pyrolyzed in the combustion tube, and the effluent gases passed through the tetrachloromercurate(II) trap. No change was noted over the blank value obtained for $\mathrm{PDA}-\mathrm{Br}$ alone.

During the pyrolysts cycle, organtc debris was seen bubbling through the tetrachloromercurate(II) trap. Several other samples of (PDA) $\mathrm{SO}_{4}$ were pyrolyzed, and the effluent gases were passed through a 5 H Solvinert filter to collect some of the organic debris. Mass spectral analysis proved that this slightly yellow materlal was $2,2^{\prime}-$ diperimidy lamine.

The next step was to optimize the operational parameters. The effect of increasing the temperature of the pyrolysis was investigated first. Increasing the temperature above $500^{\circ}$ falled to provide 
FIGURE 9

PYROLYSIS SCHEME 


\section{PYROLYTIC SULFATE METHOD}
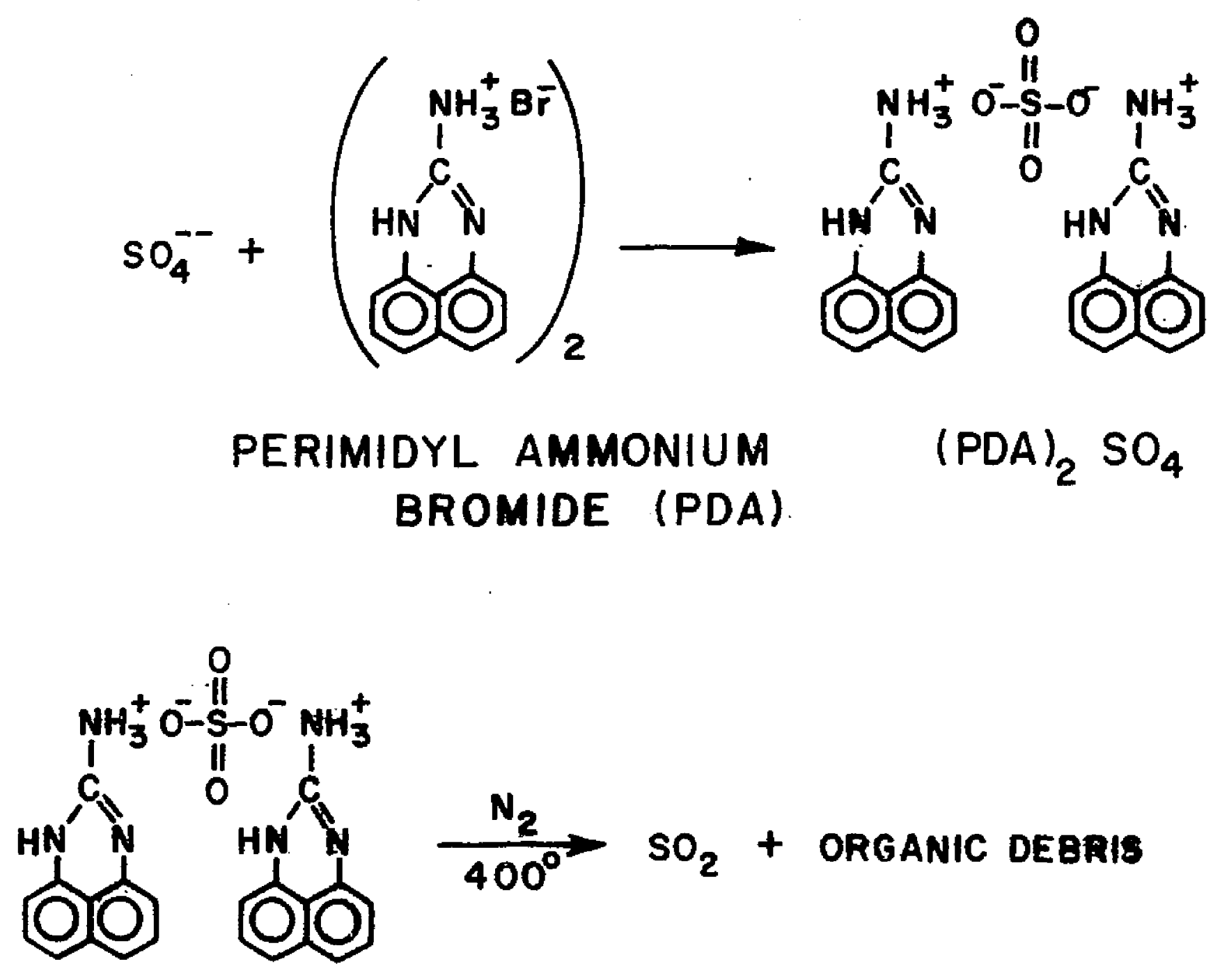
any significant increase in recovery. In fact, recovery and espectally the precision, fell with pyrolysis oven temperatures over $600^{\circ}$. As the TGA showed, a plateau exists between $450^{\circ}$ and $600^{\circ}$ after which a second slow decomposition ensues. Higher temperatures would favor reaction via the second step of decomposition which does not produce sulfur dloxide. Since the sample in the glass dish requires a finfte time to reach the operating temperature of the oven, the completeness of conversion from sulfate to sulfur dloxide will depend on the time the sample stays below $600^{\circ}$ when the pyrolysis oven is set above $600^{\circ}$. For these reasons, a pyrolysis temperature of $500^{\circ}$ was selected to provide the quickest heatup while avolding any secondary thermal reactions.

The pyrolysis time and nitrogen flow rate were set by considering the reaction rate and dead volume in the oven. The minimum reaction time was estimated by the cessation of fumes coming from the bubbler. This estimate was later verifled by using a Total Sulfur Analyzer (TSA) connected to a recorder. Figure 10 shows the flow diagram using either a Meloy SA-120 or a Bend1x 8300 Total Sulfur Analyzer. Both instruments were desfgned to operate on an atmospheric sample, so an artifictal air mixture was produced by adding oxygen to the nitrogen stream at the 3 way stopcock. These 1nstruments conflrmed that the sulfur dioxide was evolved in a sharp peak after $30-45$ seconds of heating at $500^{\circ}$, and lasted for 30 seconds after the reaction started. Since the oven chamber and combustion train contained approximately $150 \mathrm{ml}$ of dead volume, a flow rate of $500 \mathrm{ml} / \mathrm{mln}$, was chosen to provide an adequate purge during the 2.5 minute pyrolysis cycle used.

Once these experimental conditions were established, a calibration curve was made using the West-Gaeke procedure to measure the 
FIGURE 10

TOTAL SULFUR ANALYZER FLOW SYSTEM DIAGRAM 


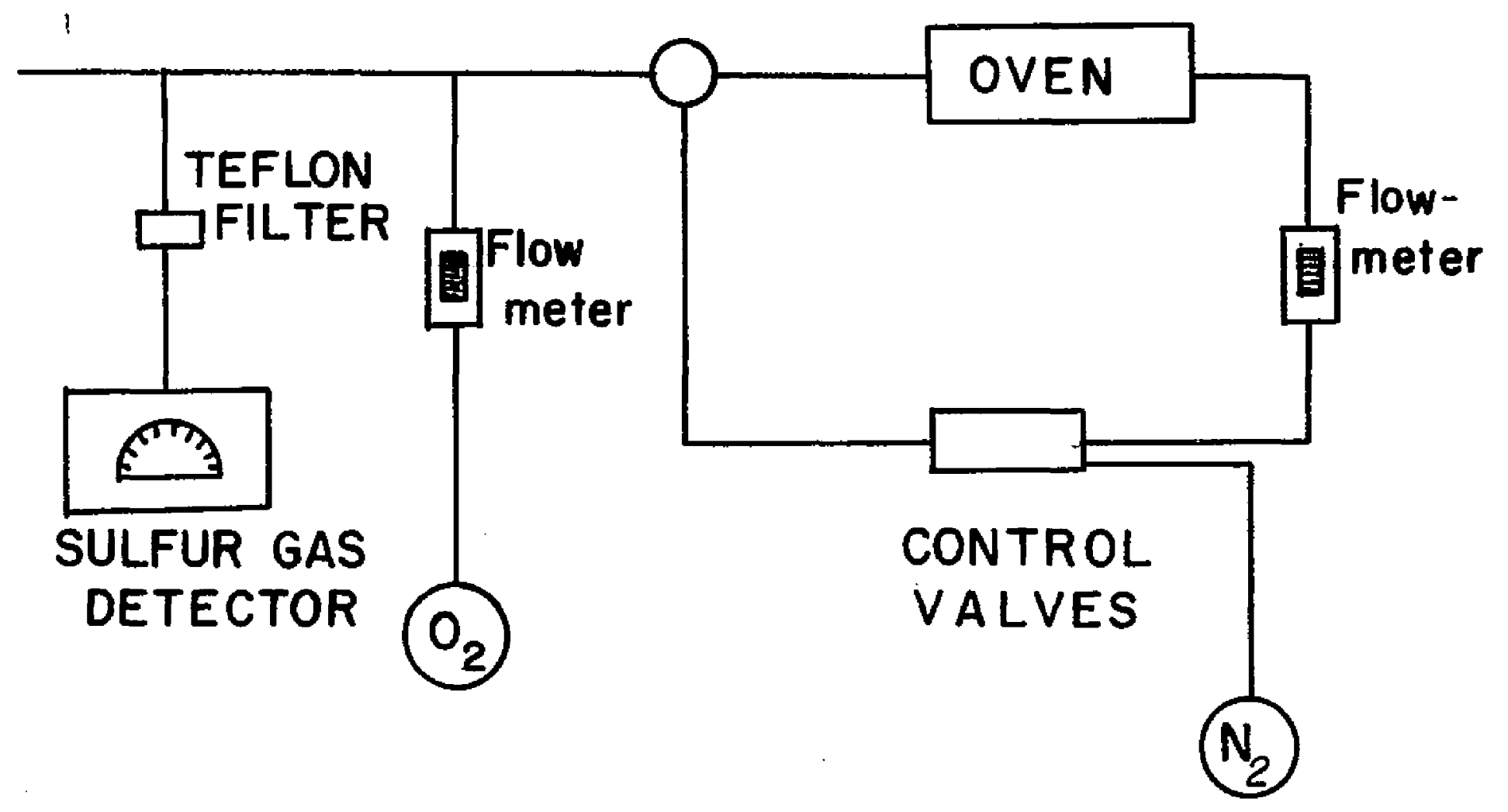


sulfur dioxide. Figure 11 shows the results of pyrolysis of 1 to $30 \mu g$ of sulfate following the cycle in the Procedure Section. In order to maintain linearity, the procedure for samples containing more than $20 \mu \mathrm{g}$ of sulfate was modifled by adding an additional $10 \mathrm{ml}$ of tetrachloromercurate(II) after the pyrolysis product was trapped. The formaldehyde and p-rosaniline additions were also doubled. This procedure produced a linear and broad range curve. Pyrolysis of $50 \mathrm{Hg}$ of sulfate was attempted with no loss in linearity. Table IV shows the results of precision and sensitivity studies. Defining the sensitivity as 2.5 times the standard deviation of the blank, the sensitivity, using the West-Gaeke procedure, would be $0.1 \mathrm{\mu g}$ of sulfate. The most significant fact of the ( $\mathrm{PDA})_{2} \mathrm{SO}_{4}$ pyrolysis is the effictency of conversion of sulfate to sulfur dloxide. Using the otandard sulfur dioxide curve for the West-Gaeke procedure, the sulfur dloxtde trapped during the pyrolysis was compared with expected sulfur dioxide output from a spectflc amount of sulfate as (PDA) $\mathrm{S}_{4^{*}}$ In all cases from 1 to $50 \mu g$ the sulfate, as (PDA) ${ }_{2} \mathrm{SO}_{4}$, was converted to sulfur doxide with $100 \%$ efflciency.

Both the Bendix and the Meloy Total Sulfur Analyzers were used in an attempt to provide real time analygis and Increase the sensttivity. The Meloy SA-120 was more flexible than the Bend $1 \times 8300$, since the range of the detector cculd be chosen by selecting the proper amplifier range on the front of the ingtrument. Both were equipped with exponential amplifiers, so the output of the instruments was linear over the entire range of 0.01 to $1 \mathrm{Hg}$ of sulfur dioxide. Figure 10 shows the flow system for pyrolysts when a Total Sulfur Analyzer was used as the detector. Surprisingly, the precision varied from \pm 6 to 
FIGURE 11

PYROLYSIS CALIBRATION GURVE 


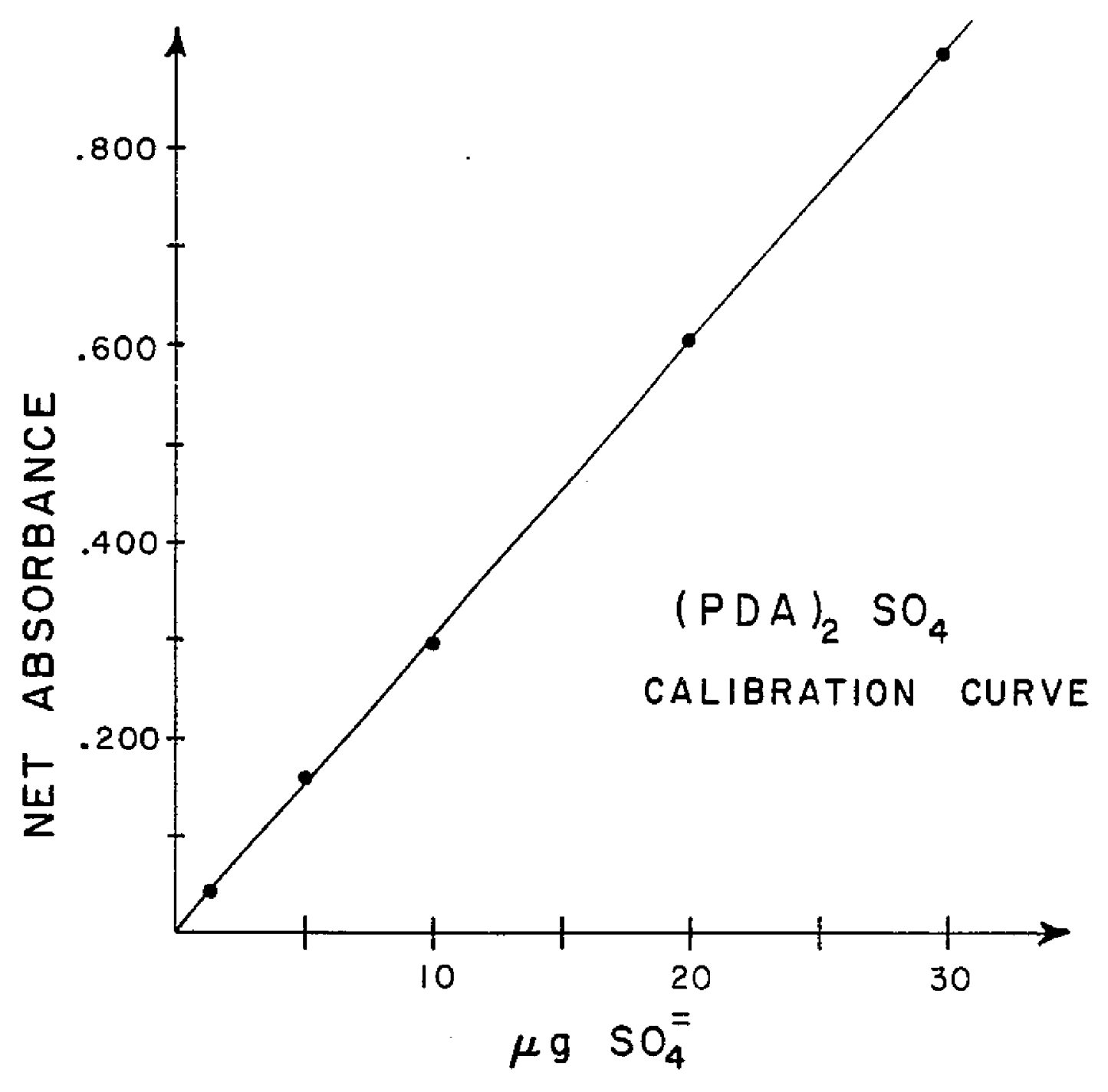


TABLE IV

PRECISION OF THE METHOD

\begin{tabular}{|c|c|c|c|c|}
\hline \multicolumn{3}{|c|}{ Blank Absorbance Values } & $10 \mu g$ Net & \multirow[t]{2}{*}{ Absorbance Values } \\
\hline & 0.033 & & & \\
\hline & 0.034 & & & 0.272 \\
\hline & 0.036 & & & 0.305 \\
\hline & 0.035 & & & 0.269 \\
\hline & 0.034 & & & 0.260 \\
\hline & 0.033 & & & 0.292 \\
\hline & 0.038 & & & 0.272 \\
\hline & 0.033 & & & 0.269 \\
\hline & 0.034 & & & 0.260 \\
\hline & 0.036 & & & 0.279 \\
\hline & 0.033 & & & 0.266 \\
\hline Avg. & $=0.034$ & & Avg. $=$ & 0.276 \\
\hline$\sigma$ & $=0.002$ & & $\sigma=$ & .015 \\
\hline Coefftcient & $t$ of Vartance & $=5.9 \%$ & Coefficte & ent of Variance $= \pm 5.3 \%$ \\
\hline
\end{tabular}


$\pm 10 \%$ at $0.5 \mu g$ of sulfate. Two factors, the organic debris and the flow system, were responsible for the poor preciston. The organic debris tended to clog the Tefion filter and vary the flow into the hydrogen flame. The nitrogen and oxygen rotameters were not able to maintain the flow rate any better than $\pm 5 \%$. As a result of these fluctuations, the precision of the Total Sulfur Analyzers was lower than that of the West-Gaeke procedure. To take advantage of the flextbility of these instruments, a hlgher degree of sophistication in the flow system would be required.

The appeal of this method lies in simplicity and flexibility. Although the chemistry Involved is somewhat sophisticated, the equipment is not. A Variac and two.Lindberg heating cylinders would work quite well as a simple constant temperature oven. By using the WestGaeke procedure to determine the sulfur dioxide evolved in the pyrolysis, the only instrument required was a typlcal laboratory spectrophotometer. Finally, as we will see in the next Chapter, the use of the thermal degradation of (PDA) ${ }_{2} \mathrm{SO}_{4}$ greatly simplifies the sulfurlc actd determination problem. 
CHAPTER V. THE MEASUREMENT OF SULFURIC ACID AEROSOL AND THE TOTAL SULFATE CONTENT OF THE AMBIENT AIR

\section{A. Previous Attempts at Measuring Sulfuric Acid Aerosol}

The foregoing chapters have shown the lack of a method for measuring sulfuric acid aerosol. Most methods for determining sulfuric acid aerosol now avallable require a great deal of a techniclan's time In extracting 33,35 or in titrating ${ }^{26}$ the acid content of the air sample. Several methods have features that, if comblned with the right analytical finish or separation step, could become useful.

As we have seen, Dubols, et al., 37 separated sulfuric acld aerosal by microdiffusion from glassfiber filters to a petri dish coated with sodium hydroxide. After the actd was collected on the sodium hydroxide, the petri dishes were rinsed and the sulfate titrated. Though the separation was simple, the analytical finish was tedious and required extremely large samples.

Scaringelli and Rehme 49 have proposed a unifled approach to sulfurtc acld aerosol determination, but their methot has several problems. Either glass fiber filters or copper impactors were used to collect the sample. As pointed out previously, glass fiber filters (Chapter III) will partially neutralize sulfuric acid aerosol while the collection efficiency of copper impactors is doubtful, especially for smaller droplets. Once a sample was collected, sulfurtc acld (vaporized from glass fiber filters) or sulfuric trloxide (produced when copper impactors were heated) was reduced over copper at $500^{\circ}$. The apparatus used required pre-conditioning with sulfuric actd, had less than $100 \%$ conversion efflctency, and had a positive interference from ammontum sulfate. 
The successful development of a method for sulfuric acid aerosol determination depends on the proper combination of collection, separation, and determination of the acid from a gross air sample. The problem of the separation was discussed in Chapter III. It was found that sulfuric acid could be separated from the filter by microdiffusion to a sultable trapping medium. During the process of heating the filter, the problem of topochemical reactions occurring on the surface of the filter between the collected partfculate matter and sulfuric actd was noted. The probability of topochemical reactions occurring increases as the amount of sample collected increases, so a decision was made to collect a small alr sample. By collecting small samples, the posslbtilty of interfering reactions was reduced, but a sensitivity problem was created. Most methods become highly unrellable at the low concentrations of sulfuric acid expected when smal1 ( $1 \mathrm{~m}^{3}$ or less) air samples are collected. In Chapter IV, a new method for sul. fate determination having a sensitivity limit of $0.1 \mathrm{Hg}$ was described. In the present chapter, the combination of microdiffusion to PDA-Br coated dishes, and subsequent pyrolysis of the (PDA) ${ }_{2} \mathrm{SO}_{4}$ formed, will be proposed as a specific sulfurtc actd aerosol method.

\section{Experimental}

\section{a. Reagents}

Refer to Chapters III and IV.

\section{b. Apparatus}

In addition to the equipment listed in Chapters III and IV, the following apparatus was employed for the analys is of atr samples for sulfuric acid and total sulfate. 
Tape sampler---Gelman Instrument Company, Mode I 23000-1 tape sample was modified by the addition of a 17 min diameter stalniess steel mesh, a $12 \mathrm{~mm}$ ID (16 mm OD) o-ring, an $8 \mathrm{~mm}$ ID (11 mm OD) 0-ring, and an $11 \mathrm{~mm}$ diameter stalnless steel mesh. These parts were layered In the sampling port in the order listed to provide support for the Fluoropore filters. Without this bulldmup support, the filters would collapse under the pressures produced by the sampling rate employed. With the sample port modifled in this manner, samples were collected over an effective diameter of approximately $12 \mathrm{~mm}$.

Glass dishes---Soft glass vials, $15 \mathrm{~mm}$ ID X $120 \mathrm{~mm}$, were cut $3 \mathrm{~mm}$ from the bottom to provide microdiffusion dishes. Vacuum desiccator---Corning No. 3118 or equivalent. Filters--Fluoropore Tefion filters $(47 \mathrm{~mm})$ of $0.5 \mu$ pore size were used to collect the sulfuric acid aerosol.

Tefion block---A $14 \mathrm{~cm} \times 7 \mathrm{~cm} \times 1 \mathrm{~cm}$ Teflon block was used to gupport the filters during microdiffusion.

Ultrasonic cleaner---Flsher ultrasonic generator, Model CT, and cleaner, Model SS-0, were used to sonicate the atr samples.

\section{c. Procedure}

The sulfurtc acid generator of Thomas, et al. ${ }^{52}$ was used to produce a standard aerosol to test the recovery of the diffusion-pyrolysis method at different levels of sulfuric acid. The resultant aerosol was sampled using a slightly modified Gelman tape sampler to produce samples containing from 2 to $40 \mathrm{~kg}$ of sulfurlc actd on the sample spot.

The Gelman tape sampler ts normally expected to operate with a $2.5 \mathrm{~cm}$ paper tape as the sampling medium. A $47 \mathrm{~mm}$ Fluoropore filter 
cut In half was slid into the collection zone, and the sulfurlc acid was collected on a $12 \mathrm{~mm}$ spot. A flowrate of approximately $4.01 / \mathrm{m} / \mathrm{n}$ was maintained throughout the sampling period. Normally, 10 satmples were collected containing like amounts of aerosol, so that 5 samples could be analyzed by the extraction procedure (Total Sulfate Method) and 5 by the diffusion-pyrolysis method (Sulfuric Acid Aerosol Method).

\section{Extraction Procedure (Total Sulfate Method)}

After the sulfuric acid samples were collected on the Fluoropore filter, a $16 \mathrm{~mm}$ diameter cork borer was used to cut away the excess filter surrounding the $12 \mathrm{~mm}$ sample spot. Thfs filter disc was placed in a $10 \mathrm{ml}$ beaker and approximately 0.5 to $1.0 \mathrm{ml}$ of the extraction solvent was added. These beakers, along with a beaker containing a blank sample of Fluoropore, were placed in a Flsher ultrasontc cleaner and sonicated for 3 minutes.

After sonication, the extract and a $0.5 \mathrm{ml}$ rinse were transferred to a $5 \mathrm{ml}$ volumetric flask. The sonication was repeated a total of 3 times for each sample.

Methanol will extract most hydrogengulfate salts and sulfurlc acid. ${ }^{36}$ since the laboratory samples contained only sulfuric actd, methanol was used as the extraction solvent. Besides the hydrogensulfate salts, an actual air sample may contain ammonium sulfate, sodium sulfate, and possible small amounts of calcium sulfate. The total sulfate can be extracted with a $50 \%$ methanol-water (v/v) solution. This mixed solvent is easier to evaporate than water alone, and will extract all the soluble sulfates present in the afr sample.

After the samples have been extracted, $2 \mathrm{ml}$ of the $5 \mathrm{ml}$ extract were put into a $15 \mathrm{~mm} X 15 \mathrm{~mm}$ ID dish containing 250 H of a $0.5 \%$ 
methanol solution of PDA-Br. The samples were allowed to atand for 10 minutes before they were placed in a vacuum desiccator, maintalned at $80^{\circ}$. A water aspirator was used to produce a vacuum and remove the solvent. The dry samples were then pyrolyzed according to the procedure outlined in Chapter IV, except that a quartz tube of the same design but with a $33 \mathrm{~mm}$ OD was used. The sulfate content of the samples was obtained by multiplying the weight of sulfur dioxide collected by $3.75 .^{*}$

\section{i1. Diffusion-Pyrolysis Method (Sulfuric Acid Aerosol}

Method)

A $15 \mathrm{~mm}$ ID X $3 \mathrm{~mm}$ dish was filled with $250 \mu I$ of a $0.5 \%$ methanol solution of PDA-Br. The solvent was evaporated in an oven at $80^{\circ}$, leaving a thin crystalline coating on the inside of the dish. A small amount of PDA-Br will crystalize on the rim of the dish, and should be removed with a cotton swab wetted with methanol. The crystalline coating was extremely cohesive and resistant to mechanical shock up to 1 ts melting point $\left(265^{\circ}\right)$.

The filter containing the sample was placed on a Teflon block and the sample spot was covered with one of the inverted PDA-Br coated dishes. The Teflon block, filter, and dish were placed in a nitrogen purged oven at $125^{\circ}$ for 2 hours, after which the dishes were removed and directly pyrolyzed (see Chapter IV). By knowing the amount of sulfur dioxide produced, the diffusion efflctency, and the sampling rate, . -

* $\left(\frac{5.0 \mathrm{ml}}{2.0 \mathrm{ml}}\right)\left(\frac{\mathrm{m} \cdot \mathrm{w} \cdot \mathrm{SO}_{4}}{\mathrm{~m} \cdot \mathrm{w} \cdot \mathrm{SO}_{2}}\right)=3.75$ 
the concentration of sulfuric acid aerosol in the amblent alr could be calculated.

B. Results and Discussion

1. Total Sulfate Method

Though the Total Sulfate Method is quite simple, there are several points to be considered while performing the procedure. It is Important to insure that the filter disc is placed sample side down in good contact with the extracting solution. If methanol is used (to remove only sulfuric acid and the common hydrogensulfates), no spectal precautions are necessary, since it w111 wet the Fluoropore.

Another significant step is the evaporation of the solvent once the sulfate has been precipitated. Although $2 \mathrm{ml}$ of solvent can be removed easily in the heated vacuum desiccator, smaller aliquots are desirable. A water solution of (PDA) $\mathrm{SO}_{4}$ will decompose slightly upon extended heating above $80^{\circ}$ in alr. The results obtalned by pyrolyzing these samples will be lower than expected. Thus, if any discoloration of the precipitate occurs during the solvent removal, the samples should be discarded. Since there is no lack of sensitivity with the pyrolysis method, the size of the aliquot for most environmental samples can be adjusted downward. A working range of 1 to $50 \mathrm{\mu g}$ sulfate in the aliquot is recommended.

To test both the accuracy and preciston of the extraction procedure, $10 \mu 1$ of a $1 \mu g / \mu 1$ (as sulfate) sodium sulfate solution were added to one-quarter of a $47 \mathrm{~mm}$ Fluoropore filter. There was some difficulty removing the last drops of the sulfate solution, since the 
Teflon surface is hydrophobic, and the pipet tips are designed to be emptied partially by capillary action. This problem was overcome by placing approximately $50 \mathrm{\mu l}$ of de-ionized water on the filter, before adding the sulfate solution. Approximately $10 \mu 1$ of the water-gulfate solution were pulled into the pipet tip and flushed out. Once the sulfate solution was on the fllter, the water was evaporated in an oven at $80^{\circ}$, and the sulfate then extracted using $50 \%$ methanol solution. The results of the extraction were quite good, as $105 \%$ of the sulfate was recovered with a coeffictent of vartance of $\pm 3.6 \%$. The recovery was greater than $100 \%$, since the sample plpet tips were rinsed while the standard pipet tips did not appear to require any additional rinsing. The results obtained using generated sulfurtc acid aerosol are sumarized in Table $v$. These values compare favorably with results obtained with sample spikes, since the prectsion of the generated aerosol samples is not better than $\pm 4 \%$. Due to the composition of most air samples, the probability of encountering any anions that would interfere with the pyrolysis of the extract is low. The sulfate content of most air samples exceeds posstble tnterferants such as phosphate, carbonate, or nitrate. If, during the extraction procedure, the dust collected becomes dislodged, a filtration step should be added to remove large quantities of suspended matter.

\section{Sulfuric Acid Aerosol Method}

The first step in measuring ambient levels of sulfurlc acid Is to separate it from the gross air sample. The microdiffusion work discussed in Chapter III has been expanded to include another filter, Fluoropore. 
TABLE V

COEFFICIENT OF VARIANCE FOR EXIRACTION PROCEDURE ANALYSIS

OF GENERATED AEROSOL SAMPLES AT SEVERAL CONCENTRATIONS

\begin{tabular}{cc}
\hline $\mathrm{g}$ Sulfuric Acid Extracted & Coefficient of Variance $(\phi)$ \\
\hline 5 & \pm 5.4 \\
9 & \pm 8.2 \\
38 & \pm 6.8
\end{tabular}


Fluoropore offers about the same chemical stability as Mitex Teflon filters, but Fluoropore comes in much smaller pore sizes. Thomas, et al. 51 have made a comparison of Millipore-MF, Whatman 41 , Poco Graphite, and Mitex Teflon using their sulfurlc acid aerosol generator. The results showed Mitex Teflon to be the least efficlent filter. This result was expected, since the Millipore filter's pore size was $0.45 \mu$ compared to $5 \mu$ for Mitex. When a similar comparison of filter efficiency between $0.45 \mu \mathrm{MF}-\mathrm{Mil1}$ ipore and $0.5 \mu \mathrm{Fluoropore}$ was made, they were found to have equivalent filtration efficlencles.

Once the relative efficlency of the $0.5 \mu$ Fluoropore was established, a study was undertaken to determine the diffuston efficiency for sulfurlc actd for varlous concentrations. A 47 man Fluoropore filter was cut into quarters and solutions of $1 \mu g / \mu 1$ sulfate as sulfurlc actd were placed on the surface. The excess liquid was evaporated, and a PDA-Br coated $15 \mathrm{~mm}$ ID $X 3 \mathrm{~mm}$ dish was centered over the sample spot. The dish, filter, and supporting glass plate were placed in an oven at $125^{\circ}$ for 6 hours. Figure 12 summarizes the results from diffusing 1 to $50 \mathrm{Hg}$ of sulfurlc acid to the $\mathrm{PDA}-\mathrm{Br}$ coated dishes, and directly pyrolyzing them after they had been removed from the diffusion oven. The data obtained were similar to the Mitex results (Figure 5), although the Fluoropore exhiblted much better recovery at the $5 \mu \mathrm{g}$ level.

In all the teats discussed so far, solutions have been evaporated to leave a residual spot of sulfuric acid on the filter. The development of an aerosol generator by our research group offered the opportunity to test the diffusion-pyrolysis method with a more representative sample. As discussed earlier (Chapter III), the spherical 
FIGURE 12

DIFFUSION FROM FLUOROPORE FILTERS FOR 6 HOURS

AT $125^{\circ}$ USING SULFURIC ACID SOLUTIONS 


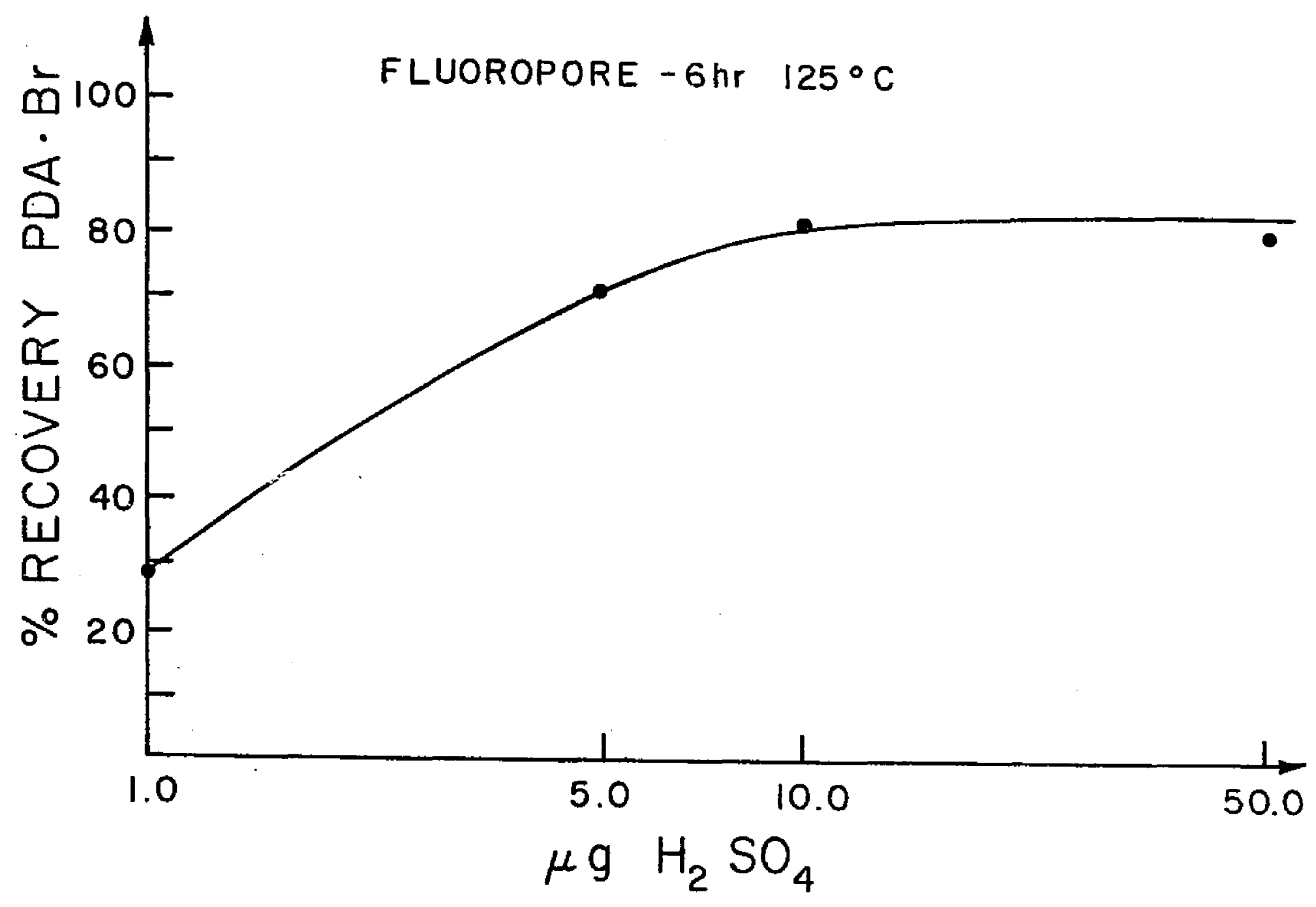


structure of an aerosol droplet means that there will be a high mass to surface contact area ratio. Consequently, since less actd is in contact with the surface of the filter, a higher percentage recovery is expected for a dispersed aerosol than for a spot of sulfurtc actd. The diffusion-pyrolysis method outlined in the Procedure Section was followed except the samples were diffused for 6 hours instead of 2 hours. The results of the dfffused and pyrolyzed aerosol samples are displayed In Figure I3. The bars Indicate the prectsion of both the extraction (horlzontal bars) and the percentage recovery (vertical bars). The $15 \%$ not recovered was due to the diffusion process, since whatever sulfuric acld evaporates will reach the PDA-Br. It has already been demonstrated that the pyrolysis of (PDA) ${ }_{2} \mathrm{SO}_{4}$ is $100 \%$ efficient for the range employed. Further evidence that the diffusion step is the limiting factor was demonstrated by the discoloration of the surface of the Fluoropore filter after heating in the diffusion oven. The prectsion of the diffuston-pyrolysis method was extremely good for points lying on the plateau ( 5 to $50 \mathrm{~kg}$ ). For artificial samples (․․‥, evaporated sulfuric acid solutions), the preclsion was $\pm 5.1 \%$ (coefficient of variance) for the diffusion-pyrolysis system. The prectsion of the diffusion-pyrolysis analysis of the generated sample is summarized in Table VI. On the whole, the precision for the diffusion-pyrolysis method is slightly more prectse than the extraction procedure.

FIgure 13 Indicates that about $1 \mu g$ of sulfuric acid can be detected. In order to obtain accurate information on the ambient con-

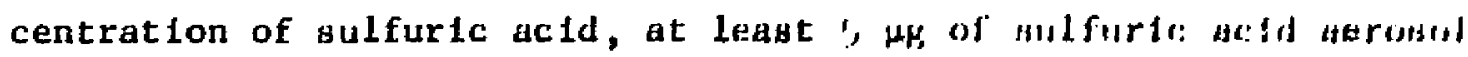
should be collected. The volume of alr needed to reach the recovery 


\section{FIGURE 13}

DIFFUSION FROM FLUOROPORE FILTERS FOR 6 HOURS AT $125^{\circ}$ USING GENERATED SULFURIC ACID AEROSOLS 


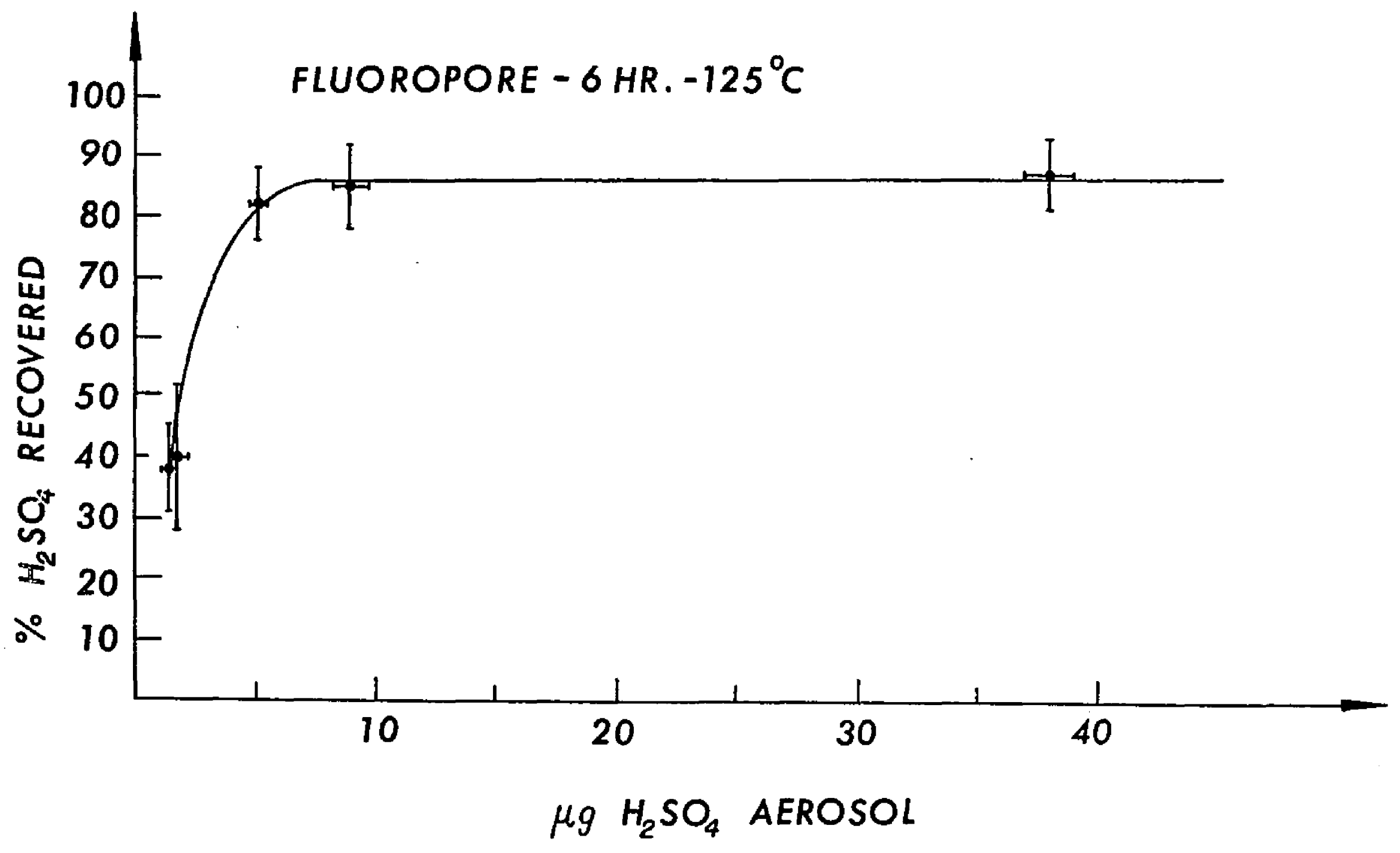


TABLE VI

COEFFICIENT OF VARIANCE FOR THE DIFFUSION PYROLYSIS ANALYSIS

OF GENERATED AEROSOL SAMPLES AT SEVERAL CONCENTRATIONS

$\mu g$ Sulfurlc Acld Diffused

Coefficient of Variance $(\$)$

4

$\pm 5.4$

8

$\pm 1.7$

33

$\pm 3.0$ 
plateau can be estimated from previous results or a sample of several cublc meters should be taken. The gulding principle in collecting an air sample is simply that the larger the volume of air sampled, the greater the possibility of neutralizing the sulfuric acid on the filter. Consequently, the smaller the volume of air sampled (within the above considerations), the better.

\section{Because of the diffusion step, very few interferants reach} the PDA-Br. Only volatile species of the afr sample would be expected to reach the $\mathrm{PDA}-\mathrm{Br}$, and of these compounds only the ammonium sulfates would interfere. In Chapter III, isothermal TGA's of ammonium sulfate were conducted at $175^{\circ}$ and $205^{\circ}$. The welght loss amounted to $1.8 \%$ and $8.2 \%$, respectively, for a 2 -hour heating. In an effort to minimize both the chemical activity of sulfuric actd and the volatility of ammonium sulfates and hydrogensulfates, the diffusion temperature was reduced to $125^{\circ}$. An 1sothermal TGA of ammonium sulfate and ammonium hydrogensulfate confirmed the fact that these compounds exhibit no volatility at $125^{\circ}$, and consequently, they would not be expected to interfere with the diffusion-pyrolysis method.

All previous diffusion studies were done on treated glass plates (Chapter III). Normally, these plates were used once and discarded, but in terms of a practical procedure this practice was wasteful. Furthermore, it was reasoned that a more inert support might allow the recovery of the $5 \%$ sulfuric actd normally lost to the glass plate. For these reasons a Teflon block of sufficlent thickness to prevent warping under heating was used to support the filter during diffusion. While no significant increase in recovery was noted over the treated glass plates, the Teflon block could be uged repeatedly. 
Previous diffuston studies presented in this Chapter and in Chapter III used a 6-hour diffusion pertod at $125^{\circ}$. Later data proved that the average recovery after 1 hour and 3 hours of diffusion was identical to the recovery obtained at 6 hours. The precision, however, for the 1-hour diffusion was slightly lower, so, as a compromise, a 2hour diffusion was recommended.

c. Summary

The results of this Chapter show that the measurement of sulfuric acid can be accomplished in a simple yet efficient procedure. By diffusing the actd to a PDA-Br coated dish, the need for further sample treatment has been eliminated. As a result, techniclans are freed from tedious procedures that require Ion exchange, extraction, or titration steps prior to or during the determination.

The equipment Involved can be found in most analytical labs. Though the equipment presented here was optimized for laboratory conditions, any varfation in design is acceptable as long as the oven can reach $500^{\circ}$ and be purged with nitrogen. Larger sampling orifices can be used allowing faster flow rates and a shorter sampling perlod. It Is hoped that the sensitivity of this method will foster the collection of hourly samples rather than the customary 24 hour high volume samples. In this way the acid content of the ambient atr can be charted in greater detail, thus significantly fncreasing our knowledge of the atmospheric sulfur cycle. 


\section{REFERENCES}

1. Lawther, P. J., Ellison, J. McK., and Waller, R. E., Proc. Roya1 Soc., Ser. A, 307, 2231 (1968).

2. Stern, A. C., ed. "Air Pollution", Academic Press, New York, 1968, Vo1. 3.

3. Leighton, P. A., "Photochemistry of Air Pollution", Pergamon Press, London (1957).

4. Train, R, Administrator of EPA, remarks before Senate Committee of Public Works, Nov. 6, 1973.

5. Amdur, M. 0., Journal Alr Pollution Control Association, 19, 638 (1969).

6. Amdur, M. 0., Schulz, R. Z., Drinker, P., Arch. Industr. Hyg. Occup. Med., 2, 318 (1952).

7. Fricket, J., "Fog Along the Meuse Valley", Trans. Faraday Soc., 32, $1192-1197$ (1936).

8. Stern, A. C., ed. "Air Pollution", Acadenic Press, New York, 1968, Vo1. I.

9. Ludwig, F. L., Coulson, D. M., and Robinson, E., "Size Distribution of Atmospheric Sulfate and Chloride Particulates" (final report). Stanford Research Inst., Menlo Park, Calif., Feb. 1966.

10. Corn, M. and Demaio, L., Journal of Alr Pollution Contro1 Association, 15, 26 (1965).

11. Roesler, J. F., Stevenson, H. J. R., and Nader, J. S., Journal Air Pollution Gontrol Association, 15, 576 (1965).

12. Wagman, J., Lee, 'R. E., and Axt, C. J., Atmospheric Enviroment, 1, $479(1967)$. 
13. Schrenk, H., Helmann, H., Glayton, G. D., Gafaffer, W. M. and Wexler, H., "Air Pollution in Donota, Pa. Epidemiology of the Unusual Smog Eplsode of October, 1948", Publ. H1th. Bul1. (Wash.) No. 306 (1949).

14. "Report of the International JoInt Commission, United States and Canada, on the Pollution of the Atmosphere in the Detroit Area", Internationa1 Joint Conm. (U.S. and Canada) Wash/Ottawa (1960).

15. Greenburg, L., Jacobs, M. B., Drolette, B. M., Field, F., and Baverman, M. M., "Report of an Air Pollution Incident in New York City, November, 1953", Pub1. H1th. Reports, I7, 7-16 (1962).

16. Commins, B. T., Analyst, 88, 364 (1963).

17. Coste, J. H. and Court1er, G. B., Trans. Faraday Soc., 32, 1198 (1936).

18. Goodeve, C. F., Trans. Faraday Soc., 르, 1218 (1936).

19. Mader, P. P. Hammino, W. J., and Bellin, A., Anal. Chem., 22 , (1950).

20. Waller, R. E., Air Water Pollution, 7, 773 (1963).

21. Derre, V. and Pfelfer, H., Gig. Sanit., 24, 68 (1969); Chem. Abs. Vo1 $71,104924 \mathrm{~m}$.

22. Horstman, S. and Wagman, J., Am. Ind. Hyg. Assooc. I., 1967, 523.

23. Horma, K. and Sakito, K., Ann. Rept. Nat1. Inst. Ind. Health (Japan), $\underline{1971}, 48$.

24. Andronov, B. E., Sergeeva, T. I., Gaeva, T. Ya, and Yudina, A. K., Sb. Navchn. Rabot Inst. Okhrany Truda Uses. Tsentr. Sov. Profsoyuzov, $\underline{6}, 89$ (1962); Chem. Abs. Vol. 60, 15142e.

25. Capkeviciene, E., Vop. Epidemiol. Gia. Litov. USSR, 1967, 205; Chem. Abs. Vo1 70, 14207e. 
26. Bavika, L. I. and Shinkarenko, L. S., Neftepererab Neftekhim, $\underline{\text {, }}$ 40 (1971); Chem. Abs. Vo1 75, 154691m.

27. E11is, B. A., "The Investigation of Atmospheric Pollution", 17th Report, H. M. Stationary office, 1931.

28. Schafer, H. N. S., Anal. Chem., 39, 1719 (1967).

29. Basargin, N. N., Metody. Anal. Khim. Reaktivov, Prep., Moscow, No. 12, 97 (1966); Chem. Abs. vol. $67,28945 u$.

30. Budensinsky, B. and Krumlova, L., Anal. Chim. Acta, 29, 375 (1967).

31. Stephen, W. I., Ana1. Chim. Acta, 50, 413 (1970).

32. Tan, L. H., and West, T. S., Analyst, 26, 281 (1971).

33. Barton, S. C. and McAdie, H. G., International Clean Air Congress, Washington, D. C., Dec. 6-11, 1970 (paper CP-TD).

34. Barton, S. C. and McAdie, H. G., Environ. Sci. and Tech., 4 (9), 769 (1970).

35. Leahy, D., Siegel, R., Klotz, P., and Newmann, L., Environ. Sci. and Tech. (in press).

36. Leahy, D., Siegel, R., Klotz, P., and Newnan, L., (Personal communication).

37. Dubois, L., Thomas, R. S., Teichman, T., and Monkman, J. L., Mikrochim Acta (Wien), 1268 (1969).

38. Dubois, L., Zdrojewski, A., Teichman, T., and Monkman, J., Int. I. Environ. Ana1. Chem., 1, 113 (1971).

39. Erdey, L., Gal, S. and Tiptay, G., Talanta, 11, 913 (1964).

40. West, P. W. and Gaeke, G. C., Anal. Chem., 28, 1816 (1956).

41. Dagnall, R. M., Thompson, K. C., and West, T. S., Analyst, $\underline{\underline{\mathscr{R}}}$ 506 (1967). 
42. Hes1inga, J., Chem. Weekbland, 22, 98 (1925).

43. Grote, W. and Kreikeler, H., Angew. Chem., 46, 106 (1938).

44. Sundberg, 0. E. and Royer, G. L., Ind. Eng. Chem., Anal. Ed., 18, $719(1946)$.

45. Peters, E. D., Rounds, G. C., and Agazzi, E. J., Anal. Chem., 24, 710 (1952).

46. Kristen, W., Ana1. Chem., 25, 74 (1953).

47. Hageman, D. B. and Faust, R. A., Ana1. Chem., 27, 1970 (1955).

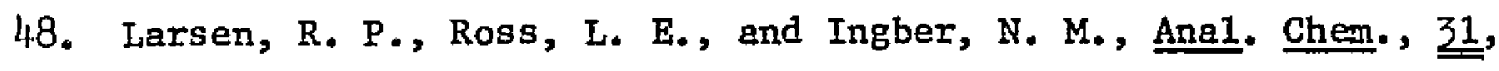
1596 (1956).

49. Scaringelli, F. P. and Rehme, K. A., Anal. Chem., 41, 707 (1969).

50. Mcclure, G. L., Anal. Chim. Acta, 64, 289 (1973).

51. Thomas, R. L., Dhamarajan, V., and West, P. W., Enviton. Sci. and Tech. (in press). 
APPENDIX I

STATISTICS

These formulas were used in calculating standard deviation(s) and coeffictent of varlance.

$$
\begin{aligned}
& \text { Standard Deviation }(s)=\left[\frac{1}{n-1} \Sigma(x-\bar{x})^{2}\right]^{\frac{1}{2}} \\
& \text { Coefficlent of Variance }=\frac{s}{\bar{x}} \times 100 \%
\end{aligned}
$$


Ray F. Maddalone was born in Hammond, Indlana, in November of 1948. After graduating from Mt. Carmel High school in Chicago, he entered the University of Notre Dame In 1966. Whtle at Notre Dame, he was a member of the fenclng team, earning two monograms. In 1970, he received his B.s. In Chemistry. Since September of 1970 , he has attended Loufsiana State University In Baton Rouge until his graduation in December of 1974 with a Ph.D. In Chemistry.

During his undergraduate education, his sumer jobs included working as a consultant in Europe for Industra Products of Ft. Wayne, Indiana; a general laborer for Stauffer Chemical Company in Hammond, Indiana; and a sumner assistant in the Chicago research labs of Nalco Chemfcal Company. Current1y, Mr. Maddalone is employed by TRW Systems, Incorporated, in Redondo Beach, California. Mr. Maddalone's hobbies Include most sports, flying, and photography. 


\section{EXAMINATION AND THESIS REPORT}

Candidate: Ray F. Maddalone

Major Field: Chemistry

Title of Thesis: The Measurement of Sulfuric Acid Aersol and the Total Sulfate Content of Ambient Air

Approved:
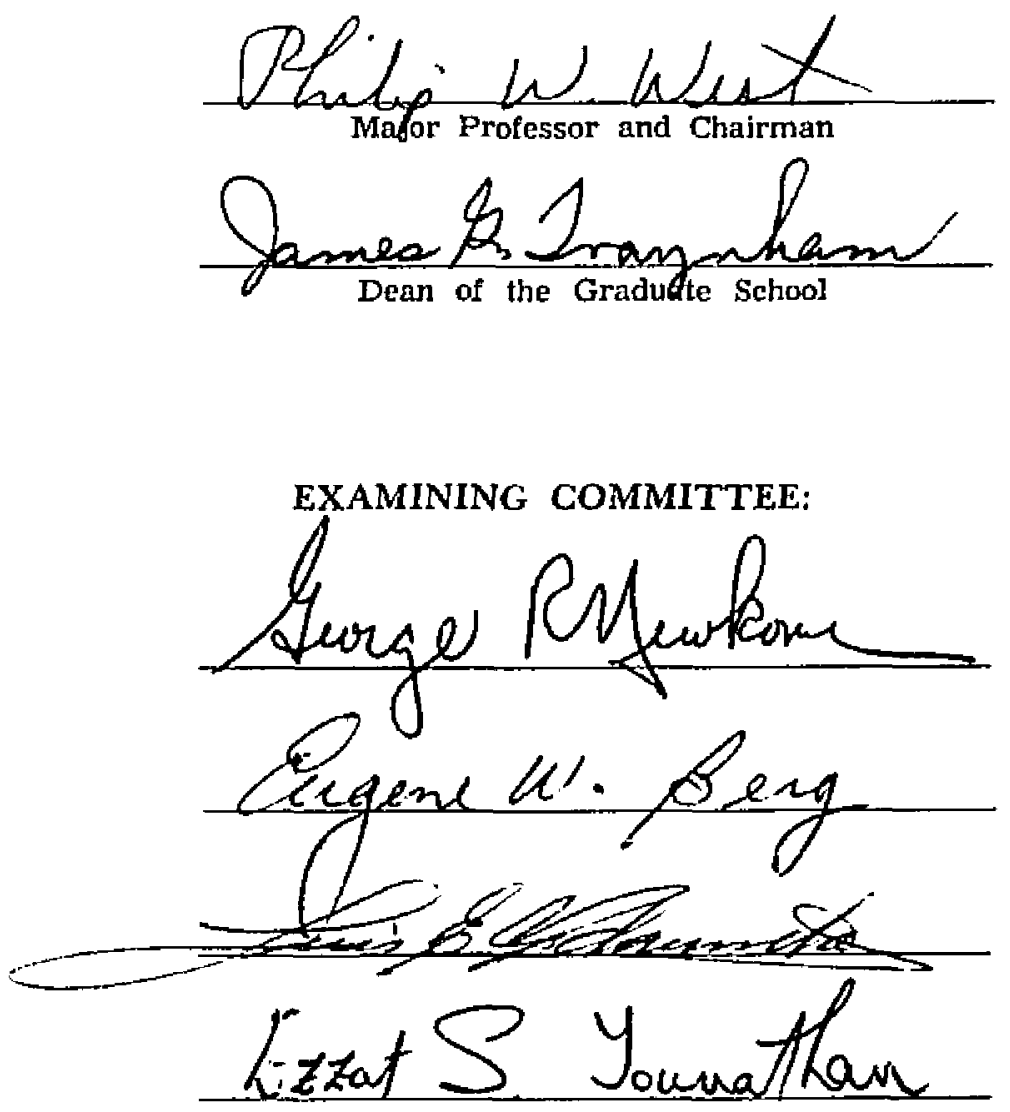

Date of Examination: 